WHC-SP-1009

Revision 1

UC-2070

\title{
Waste Sampling and Characterization Facility (WSCF)
}

Date Published

October 1994

Prepared for the U.S. Department of Energy Office of Environmental Restoration and Waste Management

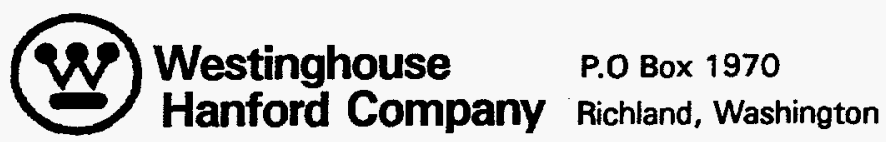

Henford Operations and Engineering Contractor for the

U.S. Department of Energy under Contract DE-AC06-87RL10930

\section{MASTER}

Approved for Public Release 


\section{DISCLAIMER}

This report was prepared as an account of work sponsored by an agency of the United States Government. Neither the United States Government nor any agency thereof, nor any of their employees, make any warranty, express or implied, or assumes any legal liability or responsibility for the accuracy, completeness, or usefulness of any information, apparatus, product, or process disclosed, or represents that its use would not infringe privately owned rights. Reference herein to any specific commercial product, process, or service by trade name, trademark, manufacturer, or otherwise does not necessarily constitute or imply its endorsement, recommendation, or favoring by the United States Government or any agency thereof. The views and opinions of authors expressed herein do not necessarily state or reflect those of the United States Government or any agency thereof. 


\section{DISCLAIMER}

\section{Portions of this document may be illegible in electronic image products. Images are produced from the best available original document.}




\section{RELEASE AUTHORIZATION}

Document Number: WHC-SP-1009, REV.1

Document Title: Waste Sampling and Characterization Facility (WSCF)

Release Date: October 11, 1994

This document was reviewed following the procedures described in WHC-CM-3-4 and is:

APPROVED FOR PUBLIC RELEASE

*************

WHC Information Release Administration Specialist:

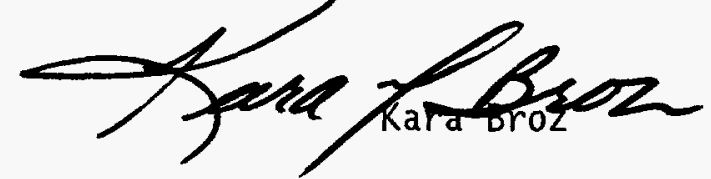

October 11, 1994

(Signature)

(Date) 


\section{APPROVALS}

Prepared By: J. R. Barber PDCS/TRP

Approved By:

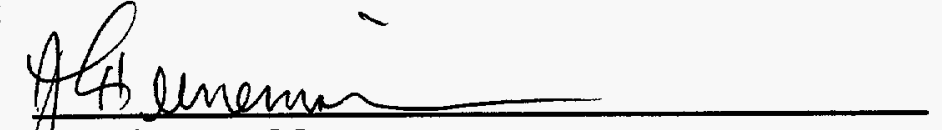

Heineman, Manager

Analytical Services Maintenance \& Work Control

Qbqonable

RR Grabbe, Manager

$\frac{10-7-94}{\text { Date }}$

Waste Sampling and Characterization Facility
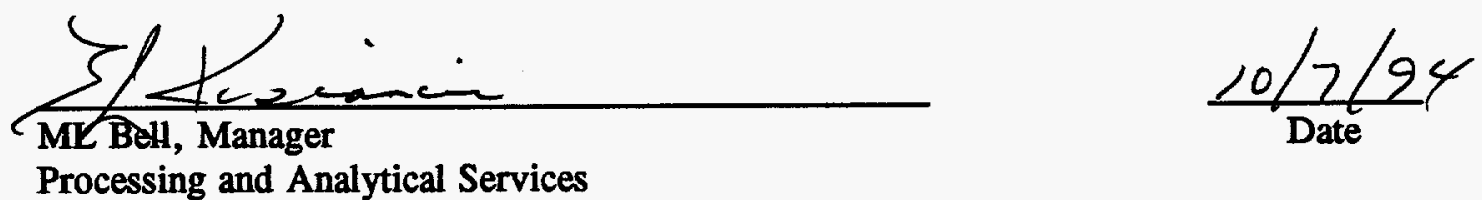

Processing and Analytical Services 


\section{FOREWORD}

This Maintenance Implementation Plan is written to satisfy the requirements of DOE Order 4330.4B, "MAINTENANCE MANAGEMENT PROGRAM", that specifies the general policy and objectives for the establishment of DOE controlled maintenance programs. These programs provide for the management and performance of cost-effective maintenance and repair of Department of Energy (DOE) property, which includes facilities.

A review of DOE Order 4330.4B, particularly Chapter II the nuclear portion, against existing WHC site programs and policies has provided assurance that most requirements of this order have already been implemented by existing WHC programs. Most requirements and applicable guidelines of 4330.4B that are deficient or not implemented are presently being developed and implemented through WHC site policies and programs. Where no program is presently identified or being developed for 4330.4B requirements, responsibility for implementation has been assigned within this plan.

In order to implement the requirements specified, this order requires a Maintenance Management Plan be developed for each new DOE controlled facility where maintenance is contractually the responsibility of DOE and where Federal funds are used totally or in part. In developing a maintenance plan for the Waste Sampling \& Characterization Facility (WSCF) a number of evaluations has been performed and the results considered for implementation. A maintainability study is performed for ergonomic and ALARA considerations of maintenance activities to maximize the accessibility of equipment and components for maintenance and minimize radiation exposure. Through a concerted maintainability design review of WSCF, an efficient and cost effective maintenance program has been implemented. 


\section{TABLE OF CONTENTS}

1.0 EXECUTIVE SUMMARY $\ldots \ldots \ldots \ldots \ldots \ldots \ldots \ldots \ldots \ldots \ldots \ldots \ldots \ldots$

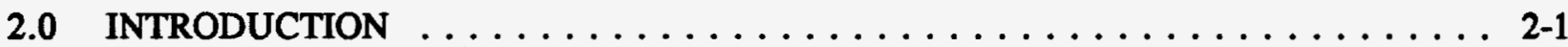

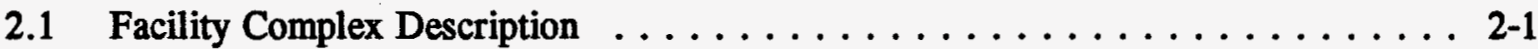

2.2 Mission $\ldots \ldots \ldots \ldots \ldots \ldots \ldots \ldots \ldots \ldots \ldots \ldots \ldots \ldots \ldots \ldots \ldots \ldots \ldots, 2$

2.3 History $/$ Scheduled Life $\ldots \ldots \ldots \ldots \ldots \ldots \ldots \ldots \ldots \ldots \ldots \ldots \ldots \ldots \ldots \ldots .2-2$

3.0 DOE ORDER 4330.4B REQUIREMENTS $\ldots \ldots \ldots \ldots \ldots \ldots \ldots \ldots \ldots \ldots$ 3-1

3.1 Maintenance Management Program Scope $\ldots \ldots \ldots \ldots \ldots \ldots \ldots \ldots . \ldots .1$

3.2 Maintenance Program Requirements $\ldots \ldots \ldots \ldots \ldots \ldots \ldots \ldots \ldots \ldots, 1$

3.3 Graded Approach Strategy $\ldots \ldots \ldots \ldots \ldots \ldots \ldots \ldots \ldots \ldots \ldots \ldots$

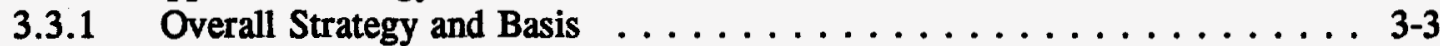

3.3.2 Strategy for Safety Related Items $\ldots \ldots \ldots \ldots \ldots \ldots \ldots \ldots \ldots$

4.0 DOE ORDER 4330.4B CHAPTER II REQUIREMENTS $\ldots \ldots \ldots \ldots \ldots \ldots \ldots$ 4-1

4.1 Evaluation of Compliance Elements $\ldots \ldots \ldots \ldots \ldots \ldots \ldots \ldots \ldots, 1$

4.2 Maintenance Organization and Administration $\ldots \ldots \ldots \ldots \ldots \ldots \ldots, 4$

4.2.1 Maintenance Organization Policies $\ldots \ldots \ldots \ldots \ldots \ldots \ldots \ldots$ 4-1

4.2.2 Maintenance Strategy . . . . . . . . . .

Working Relationships $\ldots \ldots \ldots \ldots \ldots \ldots \ldots \ldots \ldots \ldots \ldots$ 4-2

Long Range Planning $\ldots \ldots \ldots \ldots \ldots \ldots \ldots \ldots \ldots \ldots \ldots \ldots \ldots, 2$

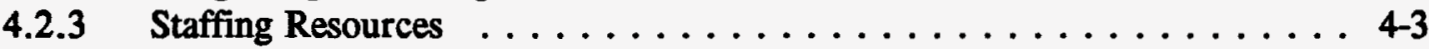

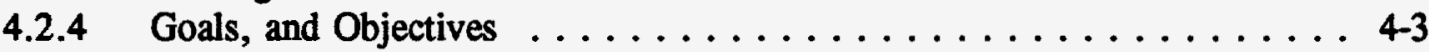

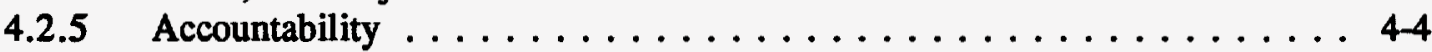

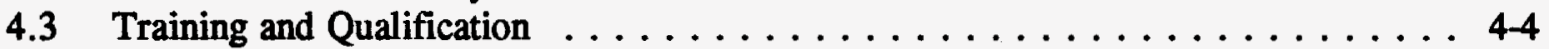

4.3.1 Responsibilities $\ldots \ldots \ldots \ldots \ldots \ldots \ldots \ldots \ldots \ldots \ldots, 4,4$

4.3.2 Maintenance Training Programs $\ldots \ldots \ldots \ldots \ldots \ldots \ldots \ldots .4 .4$

4.3.3 Training Schedules and Support $\ldots \ldots \ldots \ldots \ldots \ldots \ldots \ldots$ 4-5

4.3.4 On-the-Job Training $\ldots \ldots \ldots \ldots \ldots \ldots \ldots \ldots \ldots \ldots \ldots$

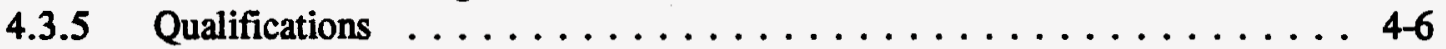

4.3.6 Training in Root Cause Analysis . . . . . . . . . . . . 4 46

4.3.7 Training Program Approval, Effectiveness, and Feedback . . . . . . 4-6

4.3.8 Management and Supervisory Training $\ldots \ldots \ldots \ldots \ldots \ldots \ldots \ldots, 4$

4.4 Maintenance Facilities, Equipment, and Tools $\ldots \ldots \ldots \ldots \ldots \ldots \ldots$ 4-7

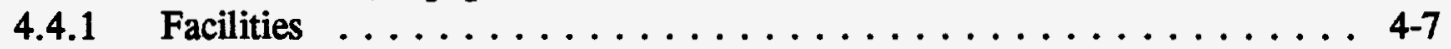

Shops and Satellite Work Areas $\ldots \ldots \ldots \ldots \ldots \ldots \ldots \ldots$ 4-7

Lay-down and Staging Area $\ldots \ldots \ldots \ldots \ldots \ldots \ldots \ldots \ldots$

Storage Facilities $\ldots \ldots \ldots \ldots \ldots \ldots \ldots \ldots \ldots \ldots \ldots \ldots \ldots$ 4-8

Temporary Facilities $\ldots \ldots \ldots \ldots \ldots \ldots \ldots \ldots \ldots \ldots \ldots \ldots$ 4-8

Decontamination Facilities $\ldots \ldots \ldots \ldots \ldots \ldots \ldots \ldots \ldots$ 4-8

4.4.2 Tool and Equipment Storage $\ldots \ldots \ldots \ldots \ldots \ldots \ldots \ldots \ldots \ldots$ 49

4.4.3 Office Equipment $\ldots \ldots \ldots \ldots \ldots \ldots \ldots \ldots \ldots \ldots \ldots .4$ 
4.5 Types of Maintenance $\ldots \ldots \ldots \ldots \ldots \ldots \ldots \ldots \ldots \ldots \ldots \ldots$. . . . . . . . . .

4.5.1 Master Equipment List $\ldots \ldots \ldots \ldots \ldots \ldots \ldots \ldots \ldots \ldots \ldots$

4.5.2 Types of Maintenance $\ldots \ldots \ldots \ldots \ldots \ldots \ldots \ldots \ldots \ldots$ 4-10

Corrective Maintenance $\ldots \ldots \ldots \ldots \ldots \ldots \ldots \ldots \ldots$ 4-10

Preventive Maintenance $\ldots \ldots \ldots \ldots \ldots \ldots \ldots \ldots \ldots$ 4-10

Predictive Maintenance $\ldots \ldots \ldots \ldots \ldots \ldots \ldots \ldots \ldots$ 4-11

4.5.3 Maintenance Action and Frequency Selection ............ 4-11

4.5.4 Scheduling $\ldots \ldots \ldots \ldots \ldots \ldots \ldots \ldots \ldots \ldots \ldots \ldots, 4,12$

4.6 Maintenance Procedures . . . . . . . . . . . . . . . . . 4 42

4.6.1 Procedure Development and Writing $\ldots \ldots \ldots \ldots \ldots \ldots \ldots, 4-12$

4.6.2 Procedure Verification $\ldots \ldots \ldots \ldots \ldots \ldots \ldots \ldots \ldots \ldots, 4,13$

4.6.4 Procedure Approval $\ldots \ldots \ldots \ldots \ldots \ldots \ldots \ldots \ldots \ldots \ldots 4,13$

4.6.5 Procedure Use $\ldots \ldots \ldots \ldots \ldots \ldots \ldots \ldots \ldots \ldots \ldots$ 4-14

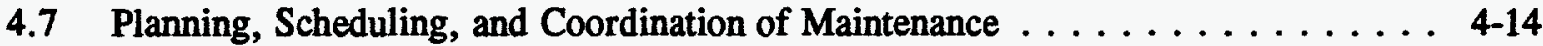

4.7.1 Planning for Maintenance Activities . . . . . . . . . . . 4 4-14

Planning Group Organization . . . . . . . . . . . . . 4-14

Planning Group Responsibilities . . . . . . . . . . . . . . . . 4-14

4.7.2 Scheduling Maintenance Activities $\ldots \ldots \ldots \ldots \ldots \ldots \ldots \ldots$ 4-15

Control of Work Backlog . . . . . . . . . . . . . . 4-15

Work Priority . . . . . . . . . . . . . . . . 4-15

4.7.3 Coordination of Maintenance Activities ............ 4-15

4.7.4 Outage Planning, Scheduling, and Coordination . . . . . . . 4-16

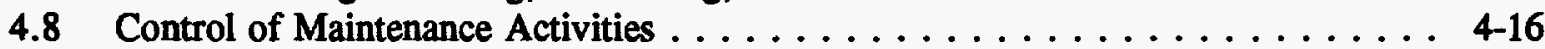

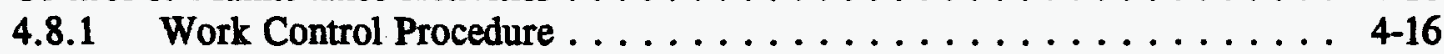

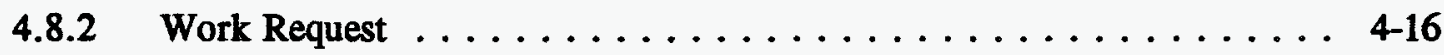

4.8.3 Supervision of Maintenance Activities $\ldots \ldots \ldots \ldots \ldots \ldots \ldots$ 4-17

4.8.4 Review of Completed Work Requests . . . . . . . . . . . 4 4-17

4.8.5 Temporary Repairs . . . . . . . . . . . . . . 4 4-18

4.8.6 Control of Nonfacility Contractor and Subcontractor Personnel . . . . . 4-18

4.9 Post-Maintenance Testing $\ldots \ldots \ldots \ldots \ldots \ldots \ldots \ldots \ldots \ldots \ldots, 4 \ldots \ldots \ldots \ldots, 18$

4.9.1 Post-Maintenance Test Requirements . . . . . . . . . . 4 4-18

4.9.2 Post-Maintenance Test Program Scope . . . . . . . . . . . . . . . 4-19

4.9.3 Post-Maintenance Test Control . . . . . . . . . . . . . . . . . . . 4-19

4.9.4 Post-Maintenance Test Performance Documentation, and Acceptance . . . 4-19

4.10 Procurement of Parts, Materials, and Services . . . . . . . . . . . 4-20

4.10.1 Procurement Policy and Procedures $\ldots \ldots \ldots \ldots \ldots \ldots \ldots \ldots .4 .20$

4.10.2 Procurement Initiation $\ldots \ldots \ldots \ldots \ldots \ldots \ldots \ldots \ldots \ldots \ldots$ 4-20

4.10.3 Procurement Control $\ldots \ldots \ldots \ldots \ldots \ldots \ldots \ldots \ldots \ldots \ldots$ 4-21

4.10 .4 Services . . . . . . . . . . . . . . . . . . . 4-21

4.11 Material Receipt, Inspection, Handling, Storage, Retrieval, and Issuance $\ldots . .4$ 4-22

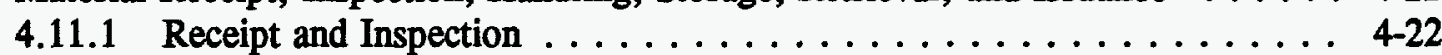

4.11 .2 Handling $\ldots \ldots \ldots \ldots \ldots \ldots \ldots \ldots \ldots \ldots \ldots \ldots \ldots \ldots \ldots \ldots \ldots, 22$

4.11.3 Storage Material and Equipment $\ldots \ldots \ldots \ldots \ldots \ldots \ldots \ldots, 4-23$

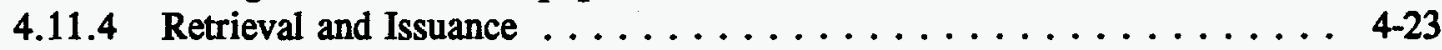


4.12 Control and Calibration of Measuring and Test Equipment . . . . . . . . . 4-24

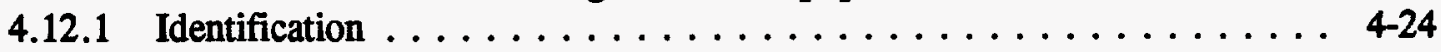

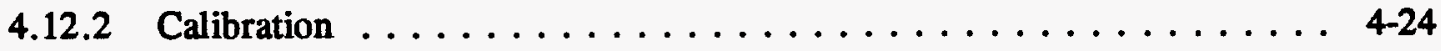

Calibration Standards . . . . . . . . . . . . . . . . . 4-24

Calibration Procedures . . . . . . . . . . . . . . . 4 4-25

Calibration Frequency . . . . . . . . . . . . . . . 4-25

Functional Checks ....................... . 4-25

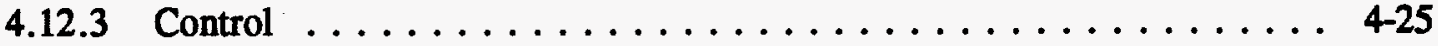

Storage ......................... 4-25

Uncalibrated M\&TE . . . . . . . . . . . . . . . . . . 4 4-26

M\&TE with Limited Use $\ldots \ldots \ldots$. . . . . . . . . . . . 4-26

Issue and Recall . . . . . . . . . . . . . . . . . . . . 4-26

Contaminated M\&TE . . . . . . . . . . . . . . . . . 4-26

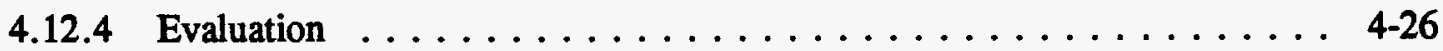

Out-of-Calibration and Defective M\&TE . . . . . . . . . . . . 4-26

Performance Trending . . . . . . . . . . . . . . . . 4-27

4.13 Maintenance Tools and Equipment Control . . . . . . . . . . . . . . . 4-27

4.13.1 Storage and Issuance $\ldots \ldots \ldots \ldots \ldots \ldots \ldots \ldots \ldots \ldots \ldots . \ldots \ldots$ 4-27

4.13.2 Tool and Equipment Maintenance . . . . . . . . . . . . 4-27

4.13.3 Use of Special Tools and Equipment $\ldots \ldots \ldots \ldots \ldots \ldots \ldots \ldots \ldots$ 4-28

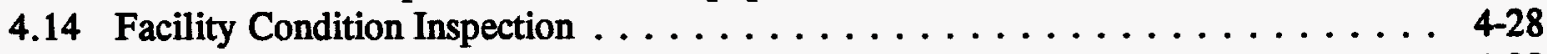

4.14 .1 Standards . . . . . . . . . . . . . . . . . . 4-28

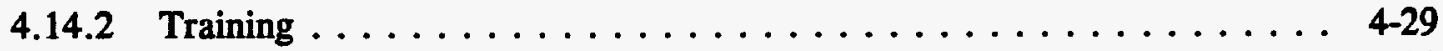

4.14 .3 Procedures ............................ 4-29

4.14.4 Scope of Inspections ... . . . . . . . . . . . . . . . 4-29

4.14.5 Inspection Program Elements . . . . . . . . . . . . . . 4-30

4.14.6 Reporting Deficiencies . . . . . . . . . . . . . . . . 4-30

4.14.7 Deficiency Follow-up $\ldots \ldots \ldots \ldots \ldots \ldots \ldots \ldots \ldots \ldots$ 4-31

4.15 Management Involvement . . . . . . . . . . . . . . . . . . 4 4-31

4.15.1 Management Involvement . . . . . . . . . . . . . 4-31

4.15.2 Performance Indicators, Goals, and Objective Results . . . . . . . . 4-32

4.15 .3 Feedback ....................... 4-32

4.15.4 Program Reviews . . . . . . . . . . . . . . . . 4-33

Assessment of Facility Condition and Worker Practices During Maintenance ...................... 4-33

Assessment of Maintenance Training . . . . . . . . . . . 4 4-34

Assessment of Procurement Activities . . . . . . . . . . . 4-34

Assessment of Measuring and Test Equipment . . . . . . . . . . . 4-34

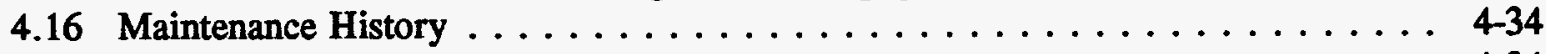

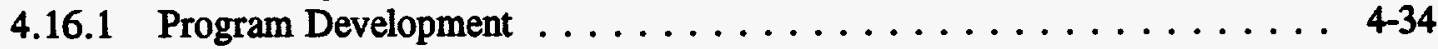

Equipment Identification . . . . . . . . . . . . . . . 4-34

Data Identification $\ldots \ldots \ldots \ldots \ldots \ldots \ldots \ldots$. . . . . . . . . . . . . .

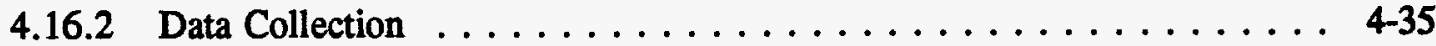

4.16 .3 Program Use ....................... 4-35 
4.17 Analysis of Maintenance Problems $\ldots \ldots \ldots \ldots \ldots \ldots \ldots \ldots \ldots .4 .35$

4.17.1 Information Collection $\ldots \ldots \ldots \ldots \ldots \ldots \ldots \ldots \ldots \ldots, 4,36$

4.17.2 Event Analysis . . . . . . . . . . . . . . . . 4-36

4.17.3 Cause Determination ................... 4-36

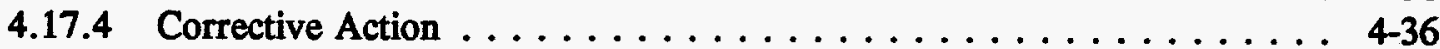

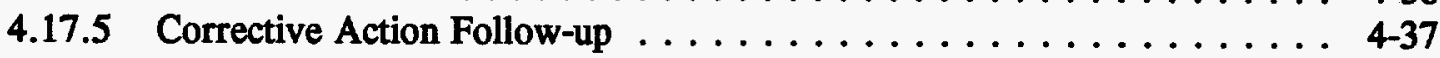

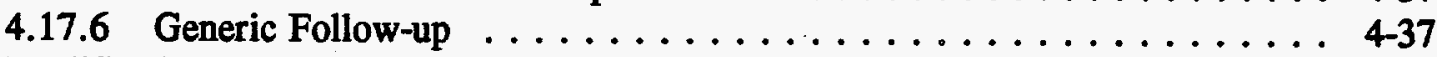

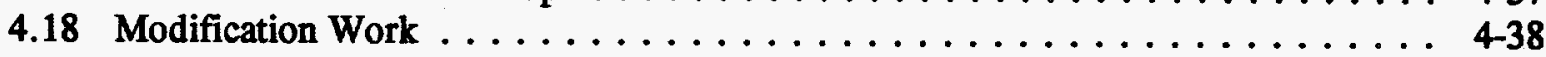

4.18.1 Maintenance Program Interface with Modifications $\ldots \ldots \ldots \ldots \ldots$ 4-38

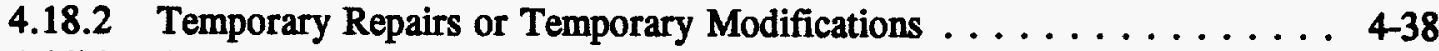

4.19 Additional Maintenance Management Requirements . . . . . . . . . . . 4-39

4.19.1 Seasonal Facility Preservation Requirements . . . . . . . . . 4-39

5.0 DEVIATIONS REQUESTED WITH SUPPORTING RATIONALE $\ldots \ldots \ldots \ldots \ldots$ 5-1

6.0 IMPLEMENTATION SCHEDULE $\ldots \ldots \ldots \ldots \ldots \ldots \ldots \ldots \ldots \ldots$ 6-1

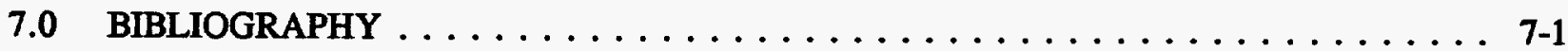




\title{
LIST OF TERMS
}

\author{
ALARA As Low As Reasonably Achievable \\ CBRS Component Based Recall System \\ CERCLA Comprehensive Environmental Response, Compensation, and Liability Act \\ DOE Department of Energy \\ EASF Environmental Archive Storage Facility \\ EDRTS Environmental Data Remedial Tracking System \\ EPA Environmental Protection Agency \\ JCS Job Control System \\ LAN Local Area Network \\ M\&TE Measuring and Test Equipment \\ MEL Master Equipment List \\ MIP Maintenance Implementation Plan \\ MLSF Mobile Laboratory Storage Facility \\ OJT On-the-Job Training \\ PM Preventive Maintenance \\ RCRA Resource Conservation and Recovery Act \\ RSME Recall Systems Maintenance Engineering Environmental Archive Facility \\ SAR Safety Analysis Report \\ SEL Safety Equipment List \\ WHC Westinghouse Hanford Company \\ WSCF Waste Sampling and Characterization Facility
}




\subsection{EXECUTIVE SUMMARY}

This Maintenance Implementation Plan has been developed for maintenance functions associated with the Waste Sampling and Characterization Facility (WSCF). This plan is developed from the guidelines presented by Department of Energy (DOE) Order 4330.4B, Maintenance Management Program (DOE 1994), Chapter II.

The objective of this plan is to provide baseline information for establishing and identifying WHC conformance programs and policies applicable to implementation of DOE order 4330.4B guidelines. In addition, this maintenance plan identifies the actions necessary to develop a costeffective and efficient maintenance program at WSCF.

The WSCF is a new facility and maintenance activities are mainly going to be performed by existing maintenance organizations within Westinghouse Hanford Corporation (WHC). Maintenance performed at WSCF is performed by the WSCF maintenance organization.

This WSCF Maintenance Implementation Plan provides the interface requirements and responsibilities as they apply specifically to WSCF. This document provides an implementation schedule which has been developed for items considered to be deficient or in need of improvement.

The discussion section as applied to WSCF implementation has been developed from a review of programs and practices utilizing the graded approach. Biennial review and additional reviews are conducted as significant programmatic and mission changes are made. This document is revised as necessary to keep this document current and in compliance with DOE requirements. 


\subsection{INTRODUCTION}

\subsection{Facility Complex Description}

The Waste Sampling and Characterization Facility (WSCF) complex consists of the main structure (WSCF) and four support structures located in the 600 Area of the Hanford site east of the $\mathbf{2 0 0}$ West area and south of the Hanford Meteorology Station. WSCF is to be used for low level sample analysis, less than $1 \mathrm{mRem}$. The Laboratory features state-of-the-art analytical and low level radiological counting equipment for gaseous, soil, and liquid sample analysis. In particular, this facility is to be used to perform Resource Conservation and Recovery Act (RCRA) of 1976 and Comprehensive Environmental Response, Compensation, and Liability Act (CERCLA) of 1980 sample analysis in accordance with U.S. Environmental Protection Agency Protocols, room air and stack monitoring sample analysis, waste water treatment process support, and contractor laboratory quality assurance checks. The samples to be analyzed contain very low concentrations of radioisotopes. The main reason that WSCF is considered a Nuclear Facility is due to the storage of samples at the facility. WSCF is divided as follows:

The Main facility consists of:

1. An Administrative support area, consisting of offices, conference room, computer area, lunchroom and change rooms are located on the main floor.

2. A nuclear Spectroscopy Laboratory is located below the Administrative Support Area but is connected to the laboratory area by means of stairs and elevators.

3. Laboratory rooms for sample preparation, organic, inorganic, radiochemistry, waste handling.

The structures supporting WSCF are:

1. The Environmental Data Remedial Tracking System Facility (EDRTS) provides a support facility for computer data center and a system training classroom.

2. The Environmental Archive Storage Facility (EASF) provides modular temperature controlled chambers for storage of samples along with storage of samples in ambient conditions.

3. The Mobile Laboratory Storage Facility (MLSF) is designed to house mobile laboratory vehicles and provide office space, a calibration and laboratory equipment room, storage areas, lunch room, and rest rooms.

4. WSCF Support Facilities:

a. A covered slab for the storage of full and empty compressed gas bottles and general storage. 
b. Solid Waste Storage building to provide temporary ( $<90$ days) storage of containerized laboratory wastes.

c. Underground Waste Storage Tanks. All sinks and hood drains from the laboratories are routed to two 1000 liter storage tanks and pumped out at lessthan-90-day intervals.

The laboratory has low level analytical equipment for gaseous, soil, and liquid sample analysis. Portal monitors are utilized for egress control of radioactive controlled areas and building egress, along with survey stations where required. HVAC and filtration of sample areas is provided through HEPA filter systems and exhaust system control. A stack monitor is installed to monitor all stack emissions. There are two separate drain systems, one for normal drainage and the other is a closed system providing the drain system for the sample areas. The sample and materials receiving area screens all incoming samples to assure they are within the guidelines of the WSCF mission and also to segregate and control contamination within WSCF.

\subsection{Mission}

The WSCF Complex is to be used to perform Resource Conservation and Recovery Act (RCRA) of 1976 and Comprehensive Environmental Response, Compensation, and Liability Act (CERCLA) of 1980 sample analysis in accordance with U.S. Environmental Protection Agency Protocols, room air and stack monitoring sample analysis, waste water treatment process support, and contractor laboratory quality assurance checks.

\subsection{History/Scheduled Life}

WSCF construction is scheduled to be completed in November 1994. This complex is being developed to support low level sample analysis in conjunction with tri-party agreement requirements. The scheduled life of the facility is projected to be for $\mathbf{3 0}$ years and is built and designed for easy decommissioning. 


\subsection{DOE ORDER 4330.4B REQUIREMENTS}

\subsection{Maintenance Management Program Scope}

The Maintenance Management Program for the WSCF encompasses all facilities and auxiliary buildings associated with the WSCF Complex. Maintenance activities associated with the WSCF are provided for, by the WSCF maintenance organization. These activities, whether for building upkeep or for repair, calibration and/or rework of analytical instrumentation or laboratory equipment, are performed by the WSCF maintenance organization. A Master Equipment List (MEL), reference section 4.0, has been developed for WSCF, as part of the design effort, per the requirements of DOE Order 4330.4B.

\subsection{Maintenance Program Requirements}

System and component maintenance requirements are established based on analyses that consider safety classifications, programmatic concerns; risk assessments of the facility, system, and component; requirements derived from technical specifications or Operations Safety Requirements; and operating experiences and maintenance history. They address the following DOE Order 4330.4B requirements:

Requirement:

The structures, systems, and components included, using a graded approach and the requirements derived from Technical Safety Requirements.

Discussion: $\quad$ A Technical Specification, Chapter 11, defines Technical Safety Requirements. The WSCF Master Equipment List (MEL) and Safety Equipment List (SEL) define the included structures, systems, and components.

Requirement: (2) The management systems used to control maintenance activities, including the means for monitoring and measuring the effectiveness of the program and the management of maintenance backlog.

Discussion: $\quad$ WSCF maintenance activities are managed and controlled in accordance with WHC-CM-1-8, "Work Management." WHC-CM-1-8 includes means for monitoring and measuring program effectiveness and backlog management through the Job Control System (JCS).

Requirement:

The assignment of responsibilities and authority for all levels of the maintenance organization.

Discussion:

Analytical Services Maintenance and Work Control Manager is responsible for maintaining a trained, qualified staff to support the maintenance needs of WSCF. The First Line Maintenance Manager is responsible for directing field work activities. 
Requirement: (4) Mechanisms for feedback of relevant information, such as trend analysis and instrumentation performance/reliability data, to identify necessary program modifications.

Discussion: $\quad$ Addressed in WHC-CM-1-8.

Requirement: (5) Provisions for identification, evaluation, and correction of possible component, system design, quality assurance, or other relevant problems.

Discussion: $\quad$ Addressed in WHC-CM-1-8.

Requirement: (6) Performance indicators and criteria to be utilized to measure equipment, systems, and personnel effectiveness in maintenance activities.

Discussion: $\quad$ Addressed in WHC-CM-1-8.

Requirement: (7) Interfaces between maintenance and other organizations (i.e., operations, engineering, quality, training, environment, safety, and health).

Discussion: $\quad$ Defined in WHC-IP-0889, "WSCF Maintenance Management Manual."

Requirement: (8) A self-assessment program to monitor the effectiveness and efficiency of the maintenance program.

Discussion: $\quad$ A self assessment program has been developed for WSCF maintenance. This self- assessment program is to be utilized at WSCF on an as needed basis to evaluate the WSCF maintenance program. As this is a new facility, an assessment of existing maintenance practices and policies is not required. Assessments of the maintenance activities at WSCF are performed when deemed appropriate or when major changes to maintenance policy and practice so warrants or as required by the Order (every two years).

Requirement: (9) Provisions for planning, scheduling, and coordination of maintenance activities.

Discussion: $\quad$ Addressed by WHC-CM-1-8 and the JCS. 


\subsection{Graded Approach Strategy}

"Graded Approach" is defined as the depth of detail required for implementation and the magnitude of resources expended for a particular maintenance management element.

\subsubsection{Overall Strategy and Basis}

A graded approach is used to identify the depth of detail and the level of commitment required to ensure safe and reliable operations, environmental compliance, programmatic mission, and facility preservation. Personnel and public safety, availability of funding, operational safety/reliability, environmental safety/compliance, safeguards and security, programmatic mission, and other facility specific requirements are to be considered when work is prioritized and performed.

At WSCF a Master Equipment List (MEL) and a Safety Equipment List (SEL) have been developed to provide designation and categorization of equipment and components as they apply to safe operation and shutdown of the facility. The MEL and SEL ensure all appropriate equipment has been identified. Maintenance activities initiated and procedures developed as a result of the safety classification ensure appropriate levels of maintenance are applied.

\subsubsection{Strategy for Safety Related Items}

System and equipment safety classification and risk categories are assigned in accordance with established Westinghouse Hanford procedures and criteria. These categories support a graded approach to maintenance activities including assignment of level of review and approval, work control, procedural detail and requirements, documentation, historical records, oversight, and methods of verification and validation. The philosophy for assignment of work priorities and allocation of resources to facility maintenance activities is for correction of discrepancies having a direct impact on facility and personnel safety; over maintenance on items not required for safe operation, or on items considered enhancements or plant betterment.

WHC-CM-3-5, "Document Control and Records Management Manual", Section 12.7, "Approval of Environmental, Safety, and Quality Affecting Documents" provides control of appropriate application of maintenance activities. 


\subsection{DOE ORDER 4330.4B CHAPTER II REQUIREMENTS}

\subsection{Evaluation of Compliance Elements}

The Hanford Site has existing programs and administrative guidelines providing for control and implementation of a maintenance program conforming to DOE Order 4330.4B. Maintenance activities at WSCF are performed in accordance with these existing documents and procedures. This Maintenance Management Plan correlates the DOE requirements to the existing program, and where appropriate defines any special maintenance program deviations and/or special program activities analogous to WSCF.

\subsection{Maintenance Organization and Administration}

The organization and administration of the maintenance function ensures a high level of performance is achieved through effective implementation and control of maintenance activities. Facility policies reflect striving for excellence in facility maintenance and operation.

\subsubsection{Maintenance Organization Policies}

Objective: To establish and communicate policies, procedures, and standards for the administration, implementation and control of maintenance activities.

Discussion: The WSCF Facility Manager is responsible for both maintenance and operational activities at WSCF. The required maintenance activities are accomplished by the maintenance organization working through the WSCF work control center.

The Analytical Services and Work Control Manager and the WSCF Maintenance Manager provide for the necessary interface within the maintenance organization and to other external organizations involved in maintenance activities at WSCF. The WSCF Operations Manager is responsible for scheduling and prioritizing maintenance activities at WSCF. All maintenance is performed per the requirements of Maintenance guidelines, applicable site procedures, and the JCS program.

Improvement: The WSCF maintenance program uses existing WHC programs and policies. Existing maintenance policies are in place and a need for any additional policies has not been identified at this time. The Maintenance Manager reviews the maintenance program and determines if any changes are necessary to the program. Applicable documents are revised as any additional requirements are identified. 


\subsubsection{Maintenance Strategy}

Objective: $\quad$ To establish an integrated approach (including all affected organizations) in performance of maintenance activities which uses strategic planning to establish specific goals for the maintenance program.

Discussion: Working Relationships

The WSCF Maintenance Manager supervises maintenance activities and coordinates any interface activities between cross discipline organizations required while performing maintenance at WSCF.

Authority, responsibility, and accountability for support organizations is governed by WHC-IP-0889 as applicable to the maintenance organization.

Control of maintenance activities is performed by the WSCF Work Control Center and the JCS as directed by the operations and maintenance organization.

\section{Discussion: $\quad$ Long Range Planning}

The WSCF Facility Manager is responsible for reviewing long-range planning of major maintenance activities and facility outages, as applicable. A scope for funding and staff resources to meet the needs of the maintenance program is provided for, through budget requests and additional funding as required.

The WSCF Maintenance Manager monitors staffing and resource requirements to assure all WSCF maintenance tasks can be supported. If any additional training is required to support a task, the Maintenance Manager allocates time for training.

The WSCF Maintenance Manager reviews scheduling requirements of facility activities to ensure adequate staffing is available during periods of anticipated facility needs. Also the manager provides to higher management justification for additional personnel and training.

Present staffing for supervisory, maintenance and work control personnel is funded for 13.8 full time equivalent (FTE).

Improvement: A program identifies and establishes long-range goals for WSCF maintenance. The Analytical Services and Work Control Manager reviews this program to ensure that these goals and objectives are in agreement with those goals and objectives approved by operations. Additional funding to support any long range plans shall be identified and where appropriate the schedule will reflect this change in budget. 


\subsubsection{Staffing Resources}

Obiective: To assemble and maintain a maintenance organization staff selected to prescribed qualification criteria commensurate with the facility mission(s), and maintaining the level of skill for maintenance personnel through training and incentive programs.

Discussion: The WSCF Maintenance Manager screens personnel to assure the skill level of the individual craftsman, is commensurate with the risk and complexity of the assigned activities. The maintenance manager provides for assessment of maintenance personnel in accordance with existing site procedures.

A periodic review of maintenance personnel training and performance is performed by the WSCF Maintenance Manager and results forwarded to the Analytical Services and Work Control Manager.

The qualifications for maintenance personnel are defined by existing site procedures and ensure personnel are trained and capable of performing work at nuclear facilities.

The WSCF Facility Manager reviews staff augmentation requirements to support outages and assigns individuals to review the qualifications of augmentation personnel to assure they adequately provide the necessary and timely support to the facility.

The Analytical Services and Work Control Manager and the WSCF Maintenance Manager reviews personnel performance and productivity, along with manager recommendations, to ensure qualified maintenance personnel are utilized. Training designed to assist deserving individuals in career progression assignments and activities is made available through existing WHC training programs.

Improvement: An evaluation of expected personnel resources has been made, and provisions for additional personnel identified. If additional resources are required, the WSCF Maintenance Manager adjusts man-loading so appropriate resources are available.

\subsubsection{Goals, and Objectives}

Objective: Establish maintenance goals to monitor maintenance activity progress, detect development of trends (favorable and unfavorable),improve performance, create a safe working environment, and measure the overall maintenance program effectiveness.

Discussion: Maintenance goals and objectives are defined for the WSCF maintenance organization in WHC-IP-0889. WSCF is committed to support the goals and objectives of the maintenance organization. 
Improvement: Specific goals for the maintenance department and established performance indicators for continued monitoring are periodically reviewed and updated for WSCF.

\subsubsection{Accountability}

Objective: To monitor personnel in the performance of their assigned responsibilities and administer recognition or disciplinary actions as appropriate to individual performance.

Discussion: Existing site procedures provide for performance reviews and critiques of maintenance personnel. WSCF Maintenance Supervision performs this task on a timely basis.

Improvement: The existing WHC program satisfies the intent of the DOE order. Periodic review is performed and additional requirements are identified and incorporated into the program.

\subsection{Training and Qualification}

A maintenance training and qualification program consistent with DOE Orders 5480.5, 5480.6, 5480.20 , and 5480.18A is established and controlled by WHC-CM-2-15. WSCF maintenance personnel are trained and qualified under the Maintenance Training Program requirements specified in WHC-IP-0889, and site specific training as specified in WHC-CM-5-4.

\subsubsection{Responsibilities}

Objective: $\quad$ Establish a maintenance training program with a clear definition of requirements and responsibilities for development and implementation. Program development includes input from maintenance managers and supervisors and be closely coordinated with the training organizations.

Discussion: The responsibility for establishing, maintaining, and implementing the maintenance training programs is defined in WHC-CM-2-15, "TRAINING ADMINISTRATION MANUAL" and WHC-IP-0889. The Maintenance Manager is responsible for coordinating the training program between the WSCF maintenance organization and the WHC training organization. This is accomplished in accordance with existing site procedures and WHC-CM-2-15.

Improvement: A formal training program for skills training specific to the job position has been developed. Specific WSCF skills are identified and the training program provides for these specialized skills. Periodic review is performed and any enhancements made.

\subsubsection{Maintenance Training Programs}


Objective: $\quad$ Maintenance training programs include courses for all functional aspects of the maintenance activity (e.g., management, planning, engineering, support functions) goals for the maintenance program.

Discussion: Maintenance training programs pertaining to managerial, supervisory, planner/scheduler, engineering, warehousing, craft positions, contractor personnel, and other positions, as deemed necessary, are accomplished in accordance with WHC-CM-2-15, WHC-CM-5-4, and WHC-IP-0889.

Improvement: Training requirements for personnel who perform functional maintenance activities is accomplished according to existing WHC procedures and programs. The training records of these personnel are reviewed, and any additional training provided for.

\subsubsection{Training Schedules and Support}

Objective: $\quad$ Training lessons are provided compatible with the individual's skills and abilities. Schedules are coordinated between maintenance managers and training organizations to ensure availability of instructors, facilities, and support requirements, as well as availability of trainees.

Discussion: The WSCF Maintenance Manager ensures training implementation is coordinated between the maintenance and the training organization, and the 222S Training Coordinator to prepare training schedules, determine attendance, and ensure qualified instructors are available to teach the courses.

Qualification of instructors is controlled by WHC site training Department in accordance with WHC-CM-2-15.

Improvement: The WSCF Maintenance Manager reviews the training records and schedules any additional training required.

\subsubsection{On-the-Job Training}

Objective: $\quad$ Formal OJT programs defining specific requirements for final qualification of personnel are outlined in WHC-IP-0889. The OJT programs is conducted by qualified OJT trainers in accordance with approved training plans.

Discussion: A formal program of on-the-job training (OJT) is in existence. As equipment is identified for OJT the Maintenance Manager ensures personnel satisfactorily complete OJT prior to being assigned work on that equipment.

Improvement: The WSCF OJT program is evolving on an as-needed basis as it is determined what lab equipment and which facility items need additional OJT requirements. This training is implemented and controlled by the WSCF Maintenance Manager. 


\subsubsection{Qualifications}

Qbjective: Maintenance management review training records and verify that all appropriate testing and/or interviews have been successfully completed before qualification of individuals for a given task.

Discussion: $\quad$ The WSCF Maintenance Manager establishes adequate records to verify qualification standards and evaluation methods to guarantee trainee competence.

The WSCF Maintenance Manager is directly involved in approving and periodically reviewing the maintenance training program.

Improvement: The program for WSCF Maintenance organization complies with existing DOE Order requirements. WSCF management continues to periodically monitor this program for conformance. There is no improvement required at this time.

\subsubsection{Training in Root Cause Analysis}

Objective: An appropriate number of individuals are trained in principles and methods of root cause analysis and various approaches to cause and effect analysis. Individuals are able to support maintenance needs and schedules.

Discussion: $\quad$ Representative WHC maintenance managers, supervisors and others trained in the principles and the methods of root cause analysis are called upon to perform this service. When needed, this team assembles and provides an independent determination of cause and effect. Personnel from other WHC organizations with the requisite training are called upon when necessary. Results are documented and a resolution is presented for further review.

Improvement: The program for WSCF Maintenance organization complies with existing DOE Order requirements. WSCF has personnel trained in root cause analysis made available to them through other WHC organizations when required. Additional WSCF personnel are used on an as-needed basis. WSCF management continues to periodically monitor this program for compliance. There is no improvement required at this time.

\subsubsection{Training Program Approval, Effectiveness, and Feedback}

Objective: The maintenance manager participates in the review and approval of the maintenance training program and training topic lesson plans. Performance of maintenance personnel is monitored for evaluation of training effectiveness, and personnel feedback is used in the effectiveness evaluation.

Discussion: The WSCF Maintenance Manager is responsible for systematically reviewing training programs to ensure trainees develop the required skills and knowledge. 
Improvement: WSCF training records are reviewed by the WSCF Maintenance Manager. Improvement in the training program, if any, is identified.

\subsubsection{Management and Supervisory Training}

Objective: $\quad$ A formalized program is in place to develop and maintain management and supervisory skills. Training provided addresses topics (e.g., personnel interfacing, communications, assessments) necessary for effective management and team building. The training program considers support of career progression for entering the supervisory and management field.

Discussion: The training department provides management and supervisory training including generic areas such as managerial and supervisory skills, accountability, assessment and observation of routine activities, communication skills, teamwork, and company management philosophies. Position-specific training is provided to first-line supervisors. All training is conducted in accordance with WHC-CM-2-15 and other existing site procedures.

Improvement: A review of management and supervisory training is performed, and any additional training identified. Present training conducted by the training department is sufficient to meet the requirements of the DOE Order. No improvement is required at this time.

\subsection{Maintenance Facilities, Equipment, and Tools}

Maintenance facilities, equipment, and tools efficiently support facility maintenance and maintenance training.

\subsubsection{Facilities}

Objective: $\quad$ Shop facilities are designed with a high consideration of industrial safety and convenience to the activities they support. Appropriate environmental control systems are provided, adequate support equipment, storage and lay-down areas are available, and controls are in place for facility use.

Discussion: $\quad$ Shops and Satellite Work Areas

A small maintenance area is provided for personnel and maintenance activities at WSCF. This area is equipped with electrical power and pneumatic supplies for bench testing and troubleshooting. The shop is multi-disciplined and supports all maintenance personnel. Storage is provided in the work area for tools and test equipment. Specialized tools and test equipment is located in the shop unless size limitations require external facilities or areas. The WSCF Maintenance Manager assesses shop size and if needed, additional space will be provided by satellite buildings or in other areas. 
The WSCF Maintenance Manager is responsible for assuring shop layout and design is conductive to a safe and efficient working environment.

The amount and type of work being performed in the shop area is normal dayto-day repair and servicing. Any specialized work requiring additional environmental controls (e.g., welding, machining, high voltage, radiation control, etc.) is performed at specific designated areas. The WSCF Maintenance Manager assesses work and determines where and under what controls the work is performed. Additional satellite work areas and stations will be provided for once a need is determined and funding becomes available.

Discussion: $\quad$ Lay-down and Staging Area

Lay-down and staging areas are provided for by the facility manager once a need for these areas becomes apparent. These areas are segregated according to radiological controls, hazardous materials, application, security requirements, and any other consideration. All areas are clearly marked and administratively controlled.

\section{Discussion: Storage Facilities}

Storage facilities for supplies and parts are provided for within the facility and on the facility grounds.

Specialized storage for radiological control is identified and controlled through HSRCM-1, "Hanford Site Radiological Control Manual", and other existing site requirements and procedures.

Storage of flammable and hazardous materials is performed in accordance with WHC-CM-4-3, "Industrial Safety Manual", and other existing site procedures.

\section{Discussion: $\quad$ Temporary Facilities}

No temporary facilities are in use at this time, but may be provided on an asneeded basis.

Discussion Decontamination Facilities

Decontamination of equipment, and tools, is performed on an as-needed basis. All contaminated equipment and tools is controlled by HSRCM-1.

Improvement: An assessment of need for additional storage areas and other maintenance areas has been made. The shop area is adequate but a shop area to support larger tools, (drill press, etc.) is needed and will be constructed as funding is available. 


\subsubsection{Tool and Equipment Storage}

Objective: $\quad$ Storage facilities are in appropriate proximity to shops and work areas to support maintenance efficiency. Appropriate environmental controls are in place for personnel and equipment protection.

Discussion: Tool and equipment storage is provided for by the Maintenance organization. Special tool and equipment storage has been identified. The WSCF Maintenance Manager addresses any need for additional storage space to the facility manager. The facility manager evaluates the need, and if appropriate, provides the maintenance department with additional storage facilities.

Improvement: Storage areas in close proximity to the work areas has been setup. Periodic reviews will be performed to ensure adequate tool and equipment storage is available. Presently meets the intent of the DOE Orders.

\subsubsection{Office Equipment}

Objective: Office equipment necessary to support an efficient maintenance program is available (e.g., furniture, computers, communications, reproduction).

Discussion: Adequate communication, calculation, reproduction, and other office equipment is provided for by WSCF facility management.

The computer department (IRM) ensures adequate terminal and interface hardware are provided at WSCF. LAN systems and file server requirements are provided for.

Improvement: Computer hardware and software along with other appropriate office equipment has been procured and installed. Any additional office equipment required will be procured as needed. No improvement required at present.

\subsection{Types of Maintenance}

A proper balance of corrective and preventative maintenance should be employed to provide a high degree of confidence facility equipment degradation is identified and corrected, that equipment life is optimized, and the maintenance program is cost effective.

\subsubsection{Master Equipment List}

Objective: Develop (and Maintain) a MEL for use in identifying equipment safety classifications and maintenance program scope, and development of the equipment history file.

Discussion: A detailed Master list of both safety-related and non-safety-related equipment, components and structures has been developed from the SAR and other design documents, and is included in the WSCF maintenance program. 
Special tools and equipment and included in the Safety Equipment List as required. The cog engineer reviews any additions to the MEL and controls additions through the ECN program.

Improvement: A review of the MEL has been conducted and determined to be complete and accurate. No improvement required at this time.

\subsubsection{Types of Maintenance}

Objective: Develop a maintenance program that establishes an appropriate, and cost effective, balance of preventive, predictive, and corrective maintenance to minimize equipment downtime and provide a high degree of confidence that facility equipment degradation is identified and corrected.

Discussion: Corrective Maintenance

WSCF maintenance personnel perform corrective maintenance activities in accordance with existing site procedures and the administrative guidelines of WHC-IP-0889. Corrective maintenance is documented and controlled in accordance with WHC-CM-1-8, "Work Management". Feedback to the cog engineer is through the JCS program and maintenance supervision. The Cog engineer evaluates the preventive maintenance program for effectiveness and changes it where necessary.

Discussion: Preventive Maintenance

The WSCF Maintenance Manager implements an effective preventive maintenance program including systems and equipment affecting safe and reliable facility operation. As part of the maintenance surveillance program, the Maintenance Manager ensures functional tests of installed equipment and/or systems (such as standby equipment or non-operating equipment scheduled for rotation) are conducted and documented. This is performed as part of post-maintenance testing activities and documented on the JCS.

Preventive maintenance is performed at predetermined and scheduled intervals, as prescribed by the Cog engineer, and seeks to maximize equipment availability. Preventive maintenance documentation provides a record of activities performed, data collected, and, where appropriate, the "as-found" and "as-left" condition of the equipment, and supplies this information to the JCS and Component Based Recall System.

The maintenance department acquires trending data as part of the maintenance surveillance program for long-term performance evaluations, such as bearing temperatures, pump speed, and vibration data.

A program for calibration and servicing of specialized laboratory equipment is integrated into the PM program. The Cog engineer is responsible for determining the type of PM and the frequency for performance. 
Discussion: Predictive Maintenance

Through the JCS status and equipment history records, the need for preventive maintenance is identified in advance of equipment failure. The WSCF Maintenance Manager has a program of data gathering which provides information for analysis, trending, and actions needed in advance of equipment failure.

The predictive maintenance program uses the equipment history program and provides information to the preventive maintenance program. When root cause analysis is performed, the resultant information is fed back into the predictive maintenance program through existing administrative guidelines and entered into the historical record.

The Cog Engineer analyzes and reviews predictive maintenance data to ensure the data collected may be successfully used to predict and address incipient failures.

Improvement: A review of WSCF has been performed to verify equipment is properly identified and can be ergonomically maintained. The existing maintenance program at WHC is adequate to maintain a maintenance program conforming to DOE Orders and guidelines. At this time no improvements, corrective actions or program enhancement are identified.

\subsubsection{Maintenance Action and Frequency Selection}

Objective: $\quad$ Maintenance frequencies are established to satisfy code and specification requirements, and to ensure optimum equipment operating life and performance.

Discussion: The Cog engineer reviews WSCF equipment history periodically to ensure PM's and their frequencies are used to improve equipment performance.

The WSCF Maintenance Manager evaluates maintenance actions and their frequencies to ensure code and regulatory requirements are being met.

The preventive maintenance program is modified as necessary from review and analysis of historical data by the WSCF Maintenance Manager. This ensures the maintenance program is cost effective and required maintenance intervals are adequate. Any change to the maintenance program is documented.

Improvement: The cog engineer identifies calibration frequencies for all applicable equipment based upon vendor recommendations, safety class, code, regulatory requirements, and historical data. No improvement needed. 


\subsubsection{Scheduling}

Objective: Preventive maintenance activities are scheduled according to assigned frequencies and in conjunction with corrective maintenance of the same equipment or with other activities related to equipment.

Discussion: The WSCF Maintenance Manager reviews the JCS periodically to determine if a proper balance of preventive to corrective maintenance activities are being performed. This review determines when it may be advantageous to perform maintenance activities on related equipment, loop components, or on equipment in close proximity. This ensures equipment maintenance is optimized, productivity is increased, and facility down time is minimized.

Improvement: The JCS database is reviewed for related corrective maintenance prior to scheduling preventive maintenance. No improvement needed.

\subsection{Maintenance Procedures}

Maintenance procedures and other work-related documents (e.g., drawings and instructions) are prepared and used to provide appropriate work direction and to ensure that maintenance is performed safely and efficiently. A balance of written guidance, craftsman's skills, and worksite supervision (graded approach) is required to achieve the quality workmanship essential to safe and reliable facility operation.

\subsubsection{Procedure Development and Writing}

Objective: $\quad$ Procedures are provided for performance of maintenance activities to any facility or equipment component designated as safety-related, has complex maintenance tasks, is beyond the skills possessed by the craftsman, or that presents a personnel or equipment hazard.

Discussion: The WSCF Manager establishes guidelines for when a procedure needs to be developed to support testing. Procedures are developed by facility engineering and the Cog Engineer, or by other WHC procedure development resources, for, and used, in all work that could result in a significant process transient, degraded facility reliability, personnel or equipment hazard, or when the complexity of the work deems a procedure appropriate. Procedures also define preventive maintenance activities.

The WSCF Maintenance Manager ensures all procedures are developed and formatted in accordance with site standards, and departmental desk instructions. 
Improvement: Maintenance procedures for preventive, predictive and corrective maintenance are developed. Procedures have been developed, using the graded approach, before associated maintenance activities are to be performed. Periodic assessment of procedure use based upon recall is performed and any unnecessary maintenance procedures identified and the appropriate action taken. The existing program meets the intent of the DOE Orders.

\subsubsection{Procedure Verification}

Objective: $\quad$ Procedures are reviewed for format and technical accuracy. Format used incorporates human factors principles and other administrative policies. Reviews are conducted by other than the procedure writer.

Discussion: The WSCF Maintenance Manager ensures all procedures are verified in accordance with WHC-CM-3-5, "Document Control and Records Management Manual", Section 12.7, "Approval of Environmental, Safety, and Quality Affecting Documents".

Improvement: Procedure validation and verification programs are periodically reviewed for conformance to DOE and WHC procedures and guidelines. Any enhancement to the program is implemented. At present the existing procedure verification program is adequate to meet the requirements of the DOE Order.

\subsubsection{Procedure Validation}

Objective: $\quad$ Procedures are reviewed for usability and correctness to ensure sufficient and understandable instructions are provided and are compatible to the equipment and task specified.

Discussion: The WSCF Maintenance Manager ensures all procedures are field validated in accordance with WHC-IP-0889 and WHC-CM-1-8.

Improvement: Validation of WSCF-specific maintenance procedures is performed by the WSCF Maintenance organization. The validation program is periodically reviewed and deficiencies corrected. There is no need for any improvement at this time.

\subsubsection{Procedure Approval}

Objective: Procedures are reviewed to applicable specifications and administrative procedures and approved by appropriate levels of management.

Discussion: The WSCF Maintenance Manager and Facility Engineering ensure all procedures are approved in accordance with WHC-CM-3-5, Section 12.7.

Improvement: All procedure approvals are made in accordance with WHC-CM-3-5, Section 12.7. There are no improvements identified or required at this time. 


\subsubsection{Procedure Use}

Objective: Procedure control is established ensuring availability and currency of the procedures to be used. Procedure compliance requirements are clearly stated, communicated, and understood by users.

Discussion: The WSCF Maintenance Manager and the JCS ensure procedures used in the field are the most current and correct revision for use. Document control issues and controls maintenance procedures per existing plant procedures.

The WSCF Maintenance Manager ensures a graded approach is used to provide the need for work procedures used by the maintenance organization and in accordance with the requirements of WHC-IP-0889 and WHC-CM-1-8.

The WSCF Maintenance Manager ensures all procedures are changed and revised in accordance with WHC-IP-0889.

Improvement: Compliance with the DOE Order is met at the present time. Periodic reviews are conducted to ensure continued compliance.

\subsection{Planning, Scheduling, and Coordination of Maintenance}

An effective system for planning, scheduling, and coordinating maintenance activities are implemented in order to ensure that maintenance is accomplished in a timely manner, improve maintenance efficiency, reduce radiation exposure, and increase equipment availability.

\subsubsection{Planning for Maintenance Activities}

Objective: $\quad$ Establish a planning program that provides work instructions, identifies resource requirements, and coordinates support functions.

Discussion: $\quad$ Planning Group Organization

The planning activities for WSCF is performed by the WSCF work control group utilizing the JCS in accordance with WHC-CM-1-8, "Work Management."

Discussion: $\quad$ Planning Group Responsibilities

The WSCF work control group is responsible for all planning activities at WSCF. The planning organization performs work activities in accordance with existing site procedures.

Improvement: The JCS and applicable site procedures comply with the DOE Order. As upgrades and enhancements to the JCS and applicable site procedures are implemented, changes are made to maintenance procedures and practices to reflect those changes. 


\subsubsection{Scheduling Maintenance Activities}

Objective: All maintenance activities are performed using a clearly defined schedule, supported by all affected organizations, tracked to maintain status, and performed according to priorities established by operations.

Discussion: Control of Work Backlog

The WSCF Operations Managers expedite work packages to assure work is performed on schedule. Work backlog is tracked and controlled within the JCS in accordance with the requirements of WHC-CM-1-8, "Work Management". The WSCF Operations Manager is responsible for reviewing the Backlog for work status and problem areas. The Scheduling of work packages and work activities is performed through the JCS, the Work Control Group, and the WSCF Operations Manager.

WSCF JCS activities are performed in accordance with applicable sections of WHC-CM-5-4, "Laboratories Administration".

Discussion: Work Priority

The WSCF Work Control Group assigns work priorities on the basis of safety and operational requirements, using the graded approach. This is controlled by the requirements of WHC-CM-1-8.

The facility manager may increase specific task work priority if deemed necessary and appropriate.

The Weekly Planning Meeting, Plan-of-the-week, and Plan-of-the-Day are used for integrating work priorities with the long range schedule.

Improvement: A maintenance plan is developed to provide a schedule for major outages and maintenance evolutions. This plan is periodically reviewed and updated to show any scheduling changes and future maintenance activities. The present program meets the intent of the DOE Orders.

\subsubsection{Coordination of Maintenance Activities}

Objective: $\quad$ Coordinate maintenance activities to ensure that work can be effectively accomplished.

Discussion: Routine planning meetings are held to ensure coordination of activities. The WSCF Maintenance Manager provides the necessary supervision to assure all maintenance activities are performed in cooperation and coordination with other departments.

Improvement: Compliance with the DOE Order is met at the present time. Periodic reviews are conducted to ensure continued compliance. 


\subsubsection{Outage Planning, Scheduling, and Coordination}

Objective: $\quad$ Establish program for identifying all maintenance activities to be performed during a defined facility or equipment outage and develop schedule for planning and performance of those activities.

Discussion: Outage planning is not applicable to WSCF as there are no systems or major pieces of equipment requiring advance scheduling and outage planning identified at this time.

Improvement: As major outages are identified, a program is established to ensure required maintenance activities are coordinated, statused and performed. There is no improvement required at this time.

\subsection{Control of Maintenance Activities}

Management directed and delegated involvement in control of maintenance activities ensure maintenance practices are effective in maintaining safe, efficient, and reliable facility operation.

\subsubsection{Work Control Procedure}

Objective: Work control is accomplished in accordance with a formal program which defines the requirements and controls for performing work. The program is used to identify all facility deficiencies, modifications, preventive maintenance and surveillance testing, avoid redundant identification of deficiencies, and post-maintenance activities.

Discussion: WHC-CM-1-8 is the administrative procedure describing work control requirements. Additional work control requirements are provided for in WHC-IP-0889 and WHC-CM-5-4.

Improvement: The WHC administrative policies and procedures applying to work control are adequate to comply with the DOE Order. There is no need for improvement at this time. Periodic review of the program is performed and any cost effective changes or enhancements will be made to the work control program as required.

\subsubsection{Work Request}

Objective: $\quad$ All maintenance activities performed are controlled by the facility work control program. Work request documents clearly define work to be performed, equipment on which work is to be performed, pre (and post) requisites, and documentation requirements. Work requests are reviewed by affected organizations before release for work and upon completion of work.

Discussion: The work request process is controlled through the application of the JCS program in accordance with WHC-CM-1-8. 
Work requests are reviewed in accordance with the requirements of WHC-CM-1-8 and WHC-CM-3-5, Section 12.7.

Improvement: The present JCS complies with the DOE Order. Periodic reviews ensure the present system remains in compliance with DOE Orders and site policies.

\subsubsection{Supervision of Maintenance Activities}

Objective: Maintenance managers routinely monitor work in progress to ensure maintenance activities are conducted in accordance with facility procedures and work package instructions. Problems observed are analyzed and feedback is provided to prevent recurrence.

Discussion: WSCF Maintenance Managers routinely monitor work in progress to help ensure maintenance activities are conducted in accordance with DOE and Site policies and procedures, per WHC job descriptions, WHC-IP-0889, and standard industry practice.

Improvement: The present supervisory and management overview of work activities complies with the DOE Order. Periodic review and re-assessment is performed to assure compliance is maintained.

\subsubsection{Review of Completed Work Requests}

Objective: Completed work packages are reviewed to verify all work items, including post-maintenance testing and inspections, have been completed in an acceptable manner before returning system or equipment to service.

Discussion: When maintenance work is performed, the WSCF Operations Manager compares the rework performed, to the post-maintenance testing or inspection result, to determine all work is acceptable prior to returning the equipment or system to normal service.

The Cog Engineer, Operations, or WSCF Maintenance Manager may request post-maintenance testing in addition to post-maintenance tests already specified on the work package, if the scope of the work performed deems additional retesting.

The Cog Engineer recommends closure of the work package after review.

Improvement: The present program and policies affecting completed work packages complies with the intent of the DOE Order. Periodic reviews of the program are performed to ensure continued compliance. 


\subsubsection{Temporary Repairs}

Objective: Temporary repairs are accomplished and controlled to the same level as permanent repairs.

Discussion: Temporary changes and modifications are performed in accordance with the requirements of WHC-CM-6-1, "Standard Engineering Practices", and JCS. Temporary repairs or changes are converted to permanent repairs or official design modifications in a timely manner, as required by applicable site procedures.

Improvement: The present program for changes complies with the DOE Order. There is no need for improvement at this time. Periodic reviews are performed to ensure continued compliance.

\subsubsection{Control of Nonfacility Contractor and Subcontractor Personnel}

Objective: Nonfacility contract and subcontract personnel who perform maintenance or modification work on WSCF facility systems are qualified for the work performed and trained in accordance with access requirements.

Discussion: $\quad$ Site procedures provide for access control and general employee training of contractor and subcontractor personnel. The WSCF operations organization assures any additional training required for contractor or subcontractor personnel is performed and documented in accordance with site procedure. Qualification of contractor personnel is certified by the contractor; and verified and documented by the cog engineer before commencement of work activities.

Improvement: This existing policy is adequate to meet the intent of the DOE Order. Periodic reviews and assessments are performed to ensure this policy is in compliance with DOE Orders and site policies.

\subsection{Post-Maintenance Testing}

Post-Maintenance testing is performed to verify components can fulfill their design function when returned to service after maintenance.

\subsubsection{Post-Maintenance Test Requirements}

Objective: $\quad$ The work completion and retest process at WHC addresses control and documentation of retest requirements. Work requests provide specific instructions for test and acceptance criteria when maintenance work is performed. 
Discussion: Post-maintenance testing is conducted in accordance with WHC-CM-1-8 when maintenance work has been performed and when specified by the $\mathrm{Cog}$ Engineer or Operations. Most repair work performed at WSCF does not require any post-maintenance testing other than an operability test, as applicable.

Improvement: Periodic review of post-maintenance testing is performed. Any identified problems are addressed and program changes implemented to correct any deficiencies. There is no need for improvement at this time.

\subsubsection{Post-Maintenance Test Program Scope}

Objective: All maintenance activities are reviewed for applicability of postmaintenance testing and appropriate testing instructions (and acceptance criteria) are provided.

Discussion: Post-Maintenance testing at WSCF is performed when the work instructions specify the requirement.

Improvement: Periodic review of post-maintenance testing is performed. Any identified problems are addressed and program changes implemented to correct any deficiencies. There is no need for improvement at this time.

\subsubsection{Post-Maintenance Test Control}

Objective: The work control program addresses control of postmaintenance testing that covers all conditions of single or multiple organization involvement and testing that is deferred until a later date.

Discussion: During work package closeout and review, retesting may be specified by operations before work package completion. If the retest can not be performed immediately and needs to be tracked, WSCF Work Control statuses and tracks the retest requirement per WHC-CM-1-8.

Improvement: Periodic review of post-maintenance testing is performed. Any identified problems are addressed and program changes implemented to correct any deficiencies. There is no need for improvement at this time.

\subsubsection{Post-Maintenance Test Performance Documentation, and Acceptance}

Objective: $\quad$ Post-maintenance testing is performed in accordance with approved work package instructions (or preventive maintenance procedure) and completion is documented.

Discussion: The JCS is used for documenting post-maintenance testing instructions unless specific test requirements are identified. Documentation is performed in accordance with work package closeout and WHC-CM-1-8 requirements. Test results are documented and retained as part of the maintenance history. 
Upon completion, the work package is reviewed for completion in accordance with WHC-CM-1-8 before approval.

Improvement: The existing program is adequate to meet the intent of the DOE Order. Periodic reviews and assessments are performed to ensure this program is in compliance with DOE Orders and site policies.

4.10 Procurement of Parts, Materials, and Services

Controls and assessment of procurement activities are used to help ensure that proper parts, materials, and services are purchased to support maintenance activities and to meet the requirements for safe and reliable facility operation.

\subsubsection{Procurement Policy and Procedures}

Objective: Policies and procedures are in place governing the procurement of parts, materials, equipment, and services. Personnel responsible for procurement activities are conversant to, and comply with, defined requirements.

Discussion: Mechanisms are in place to provide for the expeditious procurement of parts and material on a high priority basis when needed, as specified in WHC-CM-6-1 and WHC-CM-2-1, "Procurement Manual and Procedures". WHC-CM-2-2, "Material's Management Manual", prescribes methods to acquire replacement parts not available through the original supplier.

The WSCF work control center or cog engineer is responsible for procurement of parts and materials associated with WSCF maintenance activities. The WSCF Maintenance Manager is responsible for procuring parts associated with shop activities and equipment.

Equipment specified in the MEL is assessed for spare parts requirements, and any recommended spare parts procured in accordance with applicable site procedures.

Improvement: The existing program is adequate to meet the intent of the DOE Order. Periodic reviews and assessments are performed to ensure this program is in compliance with DOE Orders and site policies.

\subsubsection{Procurement Initiation}

Objective: Procurement activities are conducted in a timely fashion. The procurement program addresses the pre-selection and qualification of procurement sources, spare parts inventory, and cross facility use of inventories.

Discussion: Lessons learned from experience, such as lead times, parts usage, and supplier reliability, are factored into materials management and included in existing site procedures. 
Topics such as storage, in-storage preventive maintenance, and shelf-life requirements are addressed in WHC-CM-2-2.

Warehouse and procurement activities such as inventory, rotation, and other warehouse functions are specifically address in existing site procedures.

Improvement: The existing program is adequate to meet the intent of the DOE Order. Periodic reviews and assessments are performed to ensure this program is in compliance with DOE Orders and site policies.

\subsubsection{Procurement Control}

Objective: The procurement program provides for documentation and controls applicable to obtaining parts, materials, equipment, and services in accordance with the technical and quality requirements.

Discussion: The cog engineer approves any deviation from design specifications for parts or materials.

Warehouse personnel review material and parts activity to determine possible new additions to be included in spare parts or site stores catalog.

Procurement documents (WHC-CM-2-1) provide clear and adequate technical and quality assurance requirements consistent with design specifications.

Deficient or nonconforming items are resolved in an effective and timely manner as specified by site procedures.

Quality assurance records are controlled and maintained per WHC-CM-3-5 and WHC-CM-4-2 to provide documentation for qualified parts and materials and to ensure traceability. The QA department performs audits, inspections or surveillances of suppliers according to QA requirements.

Improvement: The existing program is adequate to meet the intent of the DOE Order. Periodic reviews and assessments are performed to ensure this program is in compliance with DOE Orders and site policies.

\subsubsection{Services}

Objective: A program for selection and procurement of service contracts is in place and a renewal process may be initiated to prevent periods of non-coverage. Service contracts include provisions for emergency or short notice support.

Discussion: Identification of the need for specialized services from vendors is made by the WSCF Maintenance and Engineering Managers to provide for timely submittal of bidding on, and awarding of contracts. 
Improvement: This area is addressed in existing procedures and impact on WSCF is addressed as required. There is no need for improvement at this time. Periodic review are performed to ensure compliance.

\subsection{Material Receipt, Inspection, Handling, Storage, Retrieval, and Issuance}

All phases of receiving, inspecting, handling, storing, retrieving, and issuing equipment, parts, and materials for maintenance are covered by effectively implemented policies and procedures consistent with the Quality Assurance Requirements of the facility.

\subsubsection{Receipt and Inspection}

Objective: $\quad$ Receipt inspections of materials and equipment is performed before acceptance for use or storage verifying items delivered conform to all procurement document requirements and are in good condition.

Discussion: WHC-CM-2-1 and WHC-CM-2-2 are prepared to specifically describe the responsibilities and techniques for receiving, inspecting, handling, storing, retrieving, and issuing equipment, parts, and materials.

Material is inspected per the requirements of WHC-CM-2-2 to ensure conformance to purchasing requirements prior to release for use and storage.

Site procedures control documentation for received material and assures that these documents are accounted for and retrievable.

WHC-CM-4-2 specifies nonconforming items are identified with tags or labels and controlled to prevent unauthorized use.

Improvement: Site procurement and receipt inspection is presently governed by existing procedures and programs and requires no improvement at this time. Review of specific application of site procedures to WSCF receipt inspection and storage are made periodically. Any additional guidance is defined in the maintenance manual (WHC-IP-0889) for receiving material and controlling their storage, as required. No improvement needed at this time.

\subsubsection{Handling}

Objective: Procedures are provided for items requiring special handling. Procedures include all information necessary to prevent damage.

Discussion: $\quad$ WHC site procedures/instructions are available for items requiring special handling.

Effective material procurement status is provided, including accurate stock records and tracking of purchase orders. 
Improvement: This area is addressed in existing procedures and impact on WSCF are addressed as required. There is no need for improvement at this time. Periodic review is performed to ensure compliance.

\subsubsection{Storage Material and Equipment}

Objective: Materials and equipment are stored in a manner to provide maximum protection, but remain readily available for issue. Safety-related equipment is segregated from nonsafety items to prevent improper usage.

Discussion: Materials are stored, protected, and identified in accordance with WHC-CM2-2 in a manner that provides ready availability for its intended use.

A shelf-life control program (WHC-CM-2-2) is provided for store items that are important to safe and reliable facility operation.

Safety-related and nonsafety-related materials and equipment are segregated from each other to prevent inadvertent use of the wrong category of item.

Periodic inspections of staging areas, stores, and warehouses are performed per the requirements of WHC-IP-0889.

The quality of stored equipment, parts, and materials is maintained in accordance with vendor information by appropriate means, such as environmental and shelf-life controls and preventive maintenance activities, if necessary.

Improvement: Warehouse storage complies with the DOE Order. Any on-sight storage is periodically evaluated for compliance to the DOE Order. Improvements to storage are made as the need is identified. There are no improvements identified or required at this time.

\subsubsection{Retrieval and Issuance}

Objective: $\quad$ Parts, materials, and equipment removed from storage are handled to the same requirements applied at time of receipt. A stores inventory system is in place to identify available materials and equipment and is available to using organizations, such as planning and engineering.

Discussion: Parts and materials issued for installation are properly controlled per existing site procedures. Unused parts and materials are promptly returned to a controlled storage area. Completed work requests/orders document material traceability. 
Improvement: Periodic review of the parts retrieval and issuance program for WSCF is performed. Unused parts and materials are promptly returned to a controlled storage area identified by the maintenance organization as parts and materials are procured for WSCF. At present the program complies with the DOE Order and there is no need for improvement at this time.

\subsection{Control and Calibration of Measuring and Test Equipment}

The program for control and calibration of measuring and test equipment (M\&TE) are consistent with the Quality Assurance requirements of DOE 5700.6C and ensure the accurate performance of facility instrumentation and equipment for testing, calibration, and repairs.

\subsubsection{Identification}

Objective: $\quad$ Establish a program for the assignment of a unique identification number for each item of M\&TE which is permanently marked or attached to the equipment and a master M\&TE equipment list for use in control of the equipment.

Discussion: All M\&TE devices used at WHC have unique identification numbers accurately identifying the specific devices and provide positive traceability. A master list identifying all M\&TE is developed and kept current by the WHC (Standards Lab) M\&TE organization.

Improvement: At WSCF there may be the need for specialized test and calibration equipment. The maintenance manager and cog engineer review M\&TE requirements and identify the need for specialized M\&TE. As these items are identified and their need is required, they are procured, tracked, and controlled, through the existing M\&TE program. Periodic review is performed to ensure program compliance to DOE Orders and site procedures. There is no need for improvement at this time.

\subsubsection{Calibration}

Objective:

Calibration of M\&TE at WHC is accomplished by qualified personnel using approved procedures and standards having full traceability to the National Institute of Standards and Technology or other nationally recognized standards. Standards utilized are maintained at designated controlled storage locations.

Discussion: $\quad$ Calibration Standards

The M\&TE calibration program is based on standards traceable to a national standard or that are recognized standards unto themselves. All traceability, administrative controls and guidelines, are already in place as part of the WHC site M\&TE program. Records are maintained at the standards lab. 
Discussion: Calibration Procedures

Procedures (WHC-CM-4-2) are used to calibrate M\&TE, control the performance of calibrations, provide repeatable calibrations, and provide acceptance criteria.

M\&TE documentation includes records for accountability and traceability of use. A recall system is developed for recalibrations of M\&TE. This system is controlled by the M\&TE Standards lab. All M\&TE calibrations are performed through the administrative controls and requirements of the M\&TE Standards lab.

Discussion: Calibration Frequency

A calibration frequency to maintain M\&TE accuracy and availability is established through the WHC M\&TE administrative program and WHC-CM4-2, "Quality Assurance Manual", section 12, "Control of Measuring and Test Equipment", requirements.

Discussion: Functional Checks

WHC site procedures recommend M\&TE be functionally checked before use and this is performed on an as-needed basis by WSCF maintenance personnel.

Improvement: The present program is in compliance with the DOE Order. Periodic review is performed to ensure program compliance to DOE Orders and site procedures. There is no need for improvement at this time.

\subsubsection{Control}

Objective: $\quad$ Control of M\&TE is established to ensure equipment used to verify (calibrate) facility instrumentation operates properly.

Discussion: $\quad$ Storage

Control of M\&TE is established by WHC-CM-4-2, Section 12, and WHC-IP-0889, to ensure equipment used to verify (calibrate) facility instrumentation operates properly.

Facilities at WSCF are provided to control storage, issuance, and calibration of M\&TE. The WSCF Maintenance Manager identifies storage areas.

Any M\&TE with suspected or actual deficiencies is segregated and marked to prohibit its use as required by existing site procedure. 
Discussion: Uncalibrated M\&TE

Any new M\&TE devices are calibrated prior to use. Uncalibrated M\&TE for taking data at WHC facilities are clearly identified and their use is strictly controlled by facility and site procedures. WSCF follows this program.

Discussion: $\quad$ M\&TE with Limited Use

M\&TE devices not fully calibrated or usable are clearly marked to indicate their limitations and are not issued for quality work at WHC. This program is also adhered.

Discussion: Issue and Recall

Log IN/OUT sheets are kept for traceability by the M\&TE custodian at WSCF M\&TE issue. The Standards Lab has administrative procedures in place for notification of calibration due dates and M\&TE recall. M\&TE usage is tracked by the maintenance department using the work request or on the calibration data sheet, if applicable. Other requirements for WSCF are in WHC-IP-0889.

Discussion: Contaminated M\&TE

Contaminated M\&TE is controlled per existing safety and radiological guidelines at WHC and is adhered to at WSCF. Contaminated M\&TE is strictly controlled to minimize the spread of contamination.

Improvement: The Maintenance Manager reviews the M\&TE program periodically for compliance. There are no improvements identified or required at this time.

\subsubsection{Evaluation}

Objective: Usage of M\&TE is controlled and evaluated to ensure proper utilization, impact/consequence of out-of-tolerance equipment use, and equipment reliability.

Discussion: Out-of-Calibration and Defective M\&TE

M\&TE devices found out of calibration or defective receive timely evaluations to determine the validity of all measurements/tests for which they were used. This is accomplished through the review of history files controlled through the CBRS (Component Based Recall System) program controlled by RSME (Recall System Maintenance Engineering). 
Discussion: $\quad$ Performance Trending

Results of M\&TE calibrations are trended by the standards lab and the Cog engineer, corrective actions are determined for any M\&TE reliability problems.

Improvement: The WSCF maintenance program uses existing WHC programs and policies. The determination for M\&TE program improvement is made during routine program assessments. There are no improvements identified or required at this time.

\subsection{Maintenance Tools and Equipment Control}

Methods are established to provide for storage, issuance, and maintenance of an adequate and readily available supply of tools and equipment and also for the development of special tools and equipment needed in the maintenance program.

\subsubsection{Storage and Issuance}

Objective: To ensure that an adequate supply of hand tools, common power tools, and equipment is readily available, properly stored, and controlled.

Discussion: Overall responsibility for assuring WSCF has proper tools to perform maintenance activities and that they are stored properly, is with the Maintenance Manager. The maintenance manager or designee reviews the WSCF MEL and determines the need for specialized tools and/or equipment. Any specialized requirements are identified and steps taken to procure the equipment if required. This specialized equipment is stored near the work site.

The Industrial Safety Manual (WHC-CM-4-3) controls the disposition of worn and defective tools along with WHC-IP-0889. The WSCF maintenance organization works to these controls and guidelines.

Improvement: The maintenance manager or designee reviews the WSCF MEL and determines the need for specialized tools and/or equipment when the need for such equipment is identified. Any specialized requirements are identified and steps taken to procure the equipment if required. Calibration gases and standards are identified and procured. Existing site policies provide for an effective program to procure and maintain specialized tools and equipment and there is no need for enhancements or improvements in the program at this time.

\subsubsection{Tool and Equipment Maintenance}

Objective: Tools and support equipment are included in the preventive maintenance program to maintain a safe use condition and to provide necessary care to maintain its service life. 
Discussion: Maintenance tools and other support equipment used at WSCF, if cost effective, are included in the preventive maintenance program by the WSCF maintenance organization.

Improvement: Existing WHC programs and policies provide for the care and servicing of tools and support equipment. Periodically this program is assessed for effectiveness and completeness. Any required improvements are identified and appropriate corrective actions taken. There is no program improvement required at this time.

\subsubsection{Use of Special Tools and Equipment}

Objective: $\quad$ Special tools and equipment are available and are clearly marked for their intended use. Work packages include necessary instructions for the proper use of special tools and equipment.

Discussion: Special tools, test rigs, special equipment, lifting and rigging equipment, and mockups required for maintenance activities at WSCF, are identified for their intended use by the WSCF maintenance organization.

Specific Instructions are provided to control the use of lifting and rigging equipment in DOE-RL-92-36, "Hanford Site Hoisting and Rigging Manual". The WSCF maintenance organization abides by these guidelines.

Improvement: Continuing assessments are made to determine the need and requirements for specialized tools and equipment. There is no need for improvement at this time.

\subsection{Facility Condition Inspection}

Management conducts periodic inspections of equipment and facilities to assure excellent facility condition, housekeeping, and safe and reliable operation.

\subsubsection{Standards}

Objective: $\quad$ Management conducts periodic inspections of equipment and facilities to assure excellent facility condition and housekeeping. The condition of a facility is dependent on many factors, including design, fabrication, modifications, ongoing maintenance, the facility work control programs, and day-to-day operation. After initial facility construction, ongoing maintenance and the control of modifications are prime contributors to keeping systems and equipment in optimum condition to support safe and reliable operation. 
Discussion: WSCF Management and Maintenance Management perform inspections of all WSCF facilities on a regular basis to ensure standards are maintained.

Managers set high facility condition and housekeeping standards and communicate them to all personnel to provide a clear understanding of these standards.

Improvement: At the present time, existing site procedures and programs comply with the intent of the DOE Order. As changes occur to the standards, inspectors receive training in the new standards.

\subsubsection{Training}

Objective: Personnel involved in facility inspections receive instructions to establish knowledge of standards and related facility policies. Methods for determining condition status are provided for consistency of inspections and condition reporting.

Discussion: The Analytical Services and Work Control Manager and the WSCF Maintenance Manager are responsible for communicating inspection criteria and techniques required to perform WSCF condition inspections as referenced in WHC-IP-0889. Safety inspection check sheets are available to the inspectors.

Improvement: At the present time the program meets the intent of the DOE Order. Periodic review is conducted to ensure continued compliance.

\subsubsection{Procedures}

Objective: Procedures are provided defining the facility inspection program, methods of implementation, standards of condition, and means for correction of deficiencies found. Deficiencies found are evaluated for changes to the facility maintenance program.

Discussion: Existing WHC procedures and WHC-IP-0889 describe the facility inspection program and good house-keeping requirements. Reporting and tracking WSCF deficiencies is provided through the JCS.

Improvement: The present system of inspections and identification of deficiencies is well defined and in compliance with the DOE Order. Periodic reviews are required to ensure continued compliance.

\subsubsection{Scope of Inspections}

Objective: Inspections include detailed walkdowns of assigned areas that include remote and limited-access areas as well as the more obvious and available areas. Key individuals are included in the inspection teams with free discussion of techniques and concerns encouraged. Sufficient time is allowed to search for 
deficiencies rather than a quick walk through. Obvious deficiencies are investigated to the degree necessary to positively identify the source of the problem.

Discussion: Inspections are performed following established WHC procedures and include walkdowns of WSCF maintenance areas. The inspections are confined to the main WSCF building and all additional out buildings where activities are performed. The facility manager is responsible for ensuring all WSCF areas and buildings are inspected on a regular basis.

Improvement: The WSCF inspection program uses existing WHC procedures and policies. Inspection routes and schedules are created to ensure all areas requiring inspection are being inspected on a routine basis. There are no improvements identified or required at this time.

\subsubsection{Inspection Program Elements}

Objective: Inspection assignments are scoped to ensure adequate time for thorough inspection and scheduled to minimize impact to ongoing operations of the facility.

Discussion: $\quad$ The WSCF Maintenance Manager establishes a scheduled walkdown inspection on a regular basis. This schedule identifies personnel assigned inspection responsibility, the area to be inspected, and any additional inspection requirements (reference WHC-IP-0889).

Improvement: The WSCF maintenance program uses existing WHC programs and policies. There are no improvements identified or required at this time.

\subsubsection{Reporting Deficiencies}

Objective: Deficiencies noted during inspection are entered into the work control program for corrective action. Significant and/or safety related deficiencies are assigned the appropriate priority and reported to the responsible facility manager. Housekeeping deficiencies are reported to the occupying organization for attention.

Discussion: Inspection results are documented and a report presented to the WSCF Manager. Items identified as deficient are tagged or identified to permit easy identification it is defective or suspect.

Significant facility condition and safety deficiencies observed are immediately reported to the shift supervisor for appropriate near-term attention. 
Improvement: The existing site program is adequate to meet the intent of the DOE Order. Periodic reassessment is performed to ensure continued compliance. There is no need for improvement at this time.

\subsubsection{Deficiency Follow-up}

Objective: $\quad$ Reported deficiencies are monitored for timely completion of corrective actions. Recurring, generic, or long term problems are analyzed for identification of root cause. Recommendations are provided for changes to the preventive maintenance program. Periodic evaluation of inspection reports and facility conditions are made to determine program effectiveness.

Discussion: Identified deficiencies requiring immediate corrective action have a work order initiated, the deficient equipment is identified, and the JCS tracks the item for corrective action. The WSCF Maintenance Manager is responsible for informing inspection personnel and concerned parties of deficiency resolutions in a timely manner, and tracking reported deficiencies to completion.

Improvement: Periodic review of this program is performed to ensure compliance. At the present time the projected program is adequate to meet the requirements of the DOE Order. There is no need for improvement at this time.

\subsection{Management Involvement}

To ensure the safety of DOE facility operations, DOE and contractor corporate and facility managers are sufficiently involved with facility operations to be technically informed and personally familiar with conditions at the operating facility.

\subsubsection{Management Involvement}

Objective: Management conducts periodic inspections of equipment and facilities to assure excellent facility condition and housekeeping. The condition of a facility is dependent on many factors, including design, fabrication, modifications, ongoing maintenance, the facility work control programs, and day-to-day operation.

After initial facility construction, ongoing maintenance and the control of modifications are prime contributors to keeping systems and equipment in optimum condition to support safe and reliable operation.

The involvement of facility managers and supervisors in periodic facility walkdowns and inspections clearly displays management standards to all personnel and can significantly improve the condition of the facility. A program for identification and dispositioning of facility condition deficiencies and housekeeping discrepancies is an important step in maintaining facilities and equipment in a condition of maximum safety, reliability, and availability. 
Discussion: The Analytical Services and Work Control Manager and the WSCF Maintenance Manager include time to personally walk through the WSCF on a routine basis. This walk through is performed to improve face-to-face communication and feedback at all levels of maintenance and to set standards for facility condition and housekeeping. Due to the size of WSCF and the types and amount of maintenance being performed, the Maintenance Manager uses the walk through as a means of assessing work load. The walk through results are documented and reviewed for short term and long term requirements as specified in WHC-IP-0889.

The WSCF Maintenance Manager ensures other appropriate personnel receive inspection techniques training and assigns inspection areas to ensure the entire facility is periodically inspected, including areas with difficult access (e.g., high radiation areas and locked areas).

Identified deficiencies are reported and corrected in a timely manner so personnel can see the positive results of the inspection program.

Improvement: The present program meets the requirements of the DOE Order; as changes to the DOE Order and site policies occur impacting management involvement, changes to the inspection program are made.

\subsubsection{Performance Indicators, Goals, and Objective Results}

Objective: $\quad$ Performance indicators are established, maintained, and trended to provide visibility of organizational goals and objectives. Information is used to observe developing trends and formation of corrective action and recovery plans.

Discussion: The WSCF Maintenance Manager uses performance indicators, goals, and objectives to establish trends and provide feedback to the maintenance organization as presented in WHC-IP-0889. These trends provide the maintenance organization with a means for assessing maintenance tasking and performance and allow for corrective action recommendations.

Improvement: Assessment of performance indicators is made periodically to ensure compliance. At present formal goals and objectives for the maintenance organization are being developed and performance indicators will be established to track goals.

\subsubsection{Feedback}

Objective: $\quad$ Feedback systems are in place to provide means for continuous communications between all groups, worker disciplines, and management levels. Methods are in place to apply lessons learned from experiences of others, and in-house, to ensure long-term success. All levels of management are available to discuss problem areas and suggested improvements. 
Discussion: Programs are in place for employees to address maintenance concerns to management. These programs are the Great Ideas Program, the Clean Sweep Program, and other employee programs. Employees may also use the chain of command and/or an appeals board to voice any concerns. The WSCF Maintenance Manager follows an open door policy enabling maintenance personnel to have direct access to management when concerns are present.

Improvement: Assessment of programs and policies regarding identification of concerns are made periodically to ensure compliance. At present the existing program is adequate to meet the requirements of the DOE Order. There is no improvement required at this time.

\subsubsection{Program Reviews}

Objective: Managers periodically review and assess all elements of the maintenance program to identify areas requiring improvement or corrective action. Input of managers and supervisors, and other supporting organizations, is utilized in program review. Areas requiring improvement are assigned for corrective action and followup.

Discussion: At WSCF the Maintenance Manager follows a program of reviews and self assessments on an as-needed basis and per the requirements of WHC-IP-0889. The feedback from self assessments and reviews determines changes to the maintenance policy of the maintenance organization. After two years of WSCF operation, a Self-Assessment is scheduled by the WSCF maintenance organization to assess maintenance activities.

\section{Discussion: Assessment of Facility Condition and Worker Practices During Maintenance}

Periodic assessments of specific programs such as the PM program are performed per site procedure. WSCF specific program evaluation is provided for by the WSCF Maintenance Manager as the need for such an evaluation becomes apparent through audits and assessments.

The WSCF Maintenance Manager periodically reviews personnel performance and work practices. This review is directed at improving worker performance. Appraisals are performed in accordance with the requirements of WHC-IP-0889.

Equipment and component maintenance history is trended through the application of the JCS program. The Cog engineer reviews this history for maintenance trends or problems. 
Discussion: $\quad$ Assessment of Maintenance Training

The maintenance organization periodically reviews the maintenance training program (WHC-IP-0889) specifically as to WSCF impact. Results of this review dictate the need, or lack there of, for training program enhancements and changes.

Discussion: $\quad$ Assessment of Procurement Activities

Periodic assessment of the procurement process are performed by the facility operations and maintenance management for timeliness and responsiveness.

Discussion: Assessment of Measuring and Test Equipment

Facility and Maintenance management assess the M\&TE organization for availability of M\&TE, and safe and reliable operational support to WSCF.

Improvement: A formalized assessment program is implemented for WSCF maintenance programs. Periodically a review is performed to ensure program compliance with the requirements of the DOE Order. At present the existing program is adequate to meet the requirements of the DOE Order. There is no improvement required at this time.

\subsection{Maintenance History}

A maintenance history and trending program is maintained to document data, provide historical information for maintenance planning, and support maintenance and performance trending of facility systems and components.

\subsubsection{Program Development}

Objective: A program is in place identifying critical (from the SAR) systems and equipment requiring documentation and retention of historical data.

Discussion: Equipment Identification

The Master Equipment List provides the identification for major or critical pieces of equipment. Maintenance history, where required, is provided through the Maintenance History Module of the JCS.

Discussion: Data Identification

Completed work packages under the JCS program include all relevant maintenance data for a given critical piece of equipment. Specific data requirements for a given piece of WSCF equipment not previously identified, are provided by the cog engineer. 
Improvement: As equipment is received or as equipment is identified for inclusion into the maintenance program, the cog engineer is responsible for review of the equipment for safety requirements, approval designators, and history requirements. This program is already in place and no further improvements is foreseen at this time. Periodic review by the maintenance organization and $\operatorname{cog}$ engineer is performed to ensure retention of history files are adequate, and compliance is still maintained.

\subsubsection{Data Collection}

Objective: Information for systems and equipment identified for record history retention is forwarded to a specified organization for control, reviewed for completeness and correctness, and entered into the equipment history program.

Discussion: Data on WSCF systems and equipment selected for history retention is controlled through Recall Systems Maintenance Engineering (RSME) and the Component Based Recall System (CBRS), Job Control System (JCS), or by data input directly to the cog engineer for analysis and trending.

Improvement: Periodic review of this program is performed to ensure the program is in compliance with the DOE Order. No improvements are identified or required at this time.

\subsubsection{Program Use}

Objective: $\quad$ Equipment history data is readily available to all organizations and is used in the development of work packages and schedules, and is periodically reviewed for developing trends.

Discussion: The JCS program establishes a maintenance history program. This program is reviewed by WSCF Maintenance Managers, cog engineers, or any personnel involved with WSCF maintenance to identify problems or areas where maintenance activities may not be warranted.

Improvement: Periodic review of this program is performed to ensure the program is in compliance with the DOE Order. No improvements are identified or required at this time.

\subsection{Analysis of Maintenance Problems}

Systematic analysis is used to determine and correct root causes of unplanned occurrences related to maintenance. 


\subsubsection{Information Collection}

Objective: In preparation of event analysis, all applicable logs, records, recordings, and personnel interview statements are gathered.

Discussion: WSCF maintenance activities are mainly confined to environment control systems, analytical instrumentation, and to building utilities. Maintenance and calibration of special lab equipment is performed and this information is tracked and statused.

Improvement: Periodic review by the maintenance organization is performed to ensure necessary data is being retained for equipment history files. The present program satisfies the intent of the DOE order. No improvement is required at this time.

\subsubsection{Event Analysis}

Objective: In performing an event analysis a detailed sequence of facts and activities is developed and apparent causal factors identified and categorized.

Discussion: Aspects of root-cause-analysis are presently addressed in site procedures. The activities required by event analysis are performed in accordance with root-cause-analysis procedures and guidelines at WSCF.

Improvement: The present program satisfies the intent of the DOE order. No improvement is required at this time.

\subsubsection{Cause Determination}

Objective: Actual or probable causes of a problem are evaluated by one or more techniques to establish a final root cause. Appropriate documentation is developed to aid in the analysis, to record analysis performed, and to document corrective action recommendations.

Discussion: WSCF personnel performing cause determination are trained in Root-CauseAnalysis and perform activities in accordance with existing site procedures.

Improvement: Periodic review is performed to determine program compliance. If additional training is identified as being needed, training is provided to personnel to assist senior staff. The present site Root-Cause-Analysis program satisfies the intent of the DOE order. No improvement is required at this time.

\subsubsection{Corrective Action}

Objective: $\quad$ Corrective action plans are developed, initiated, and tracked to completion. Plans address all applicable activities such as repairs, preventive maintenance procedures, and personnel training. 
Discussion: Once cause determination has been performed, corrective action is initiated in accordance with WHC site procedure and tracked by the WSCF Maintenance Manager to completion.

Improvement: As corrective action is required at WSCF, the WSCF Maintenance Manager assesses the plan and makes any necessary changes or enhancements to assure corrective action is implemented and completed. Existing site procedures and policies are adequate to meet the intent of the DOE Order. No improvement is required at this time.

\subsubsection{Corrective Action Follow-up}

Objective: Corrective action followup activities include specific post repair testing and continued monitoring of equipment as positive means to ensure corrective actions taken in fact resolve the problem experience.

Discussion: Equipment corrective action is followed by some type of post-maintenance testing and tracked by the JCS. Procedural or administrative changes are followed by the WSCF Maintenance Manager and the training organization.

Improvement: Existing site procedures and policies are adequate to meet the intent of the DOE Order. No improvement is required at this time.

\subsubsection{Generic Follow-up}

Objective: Analysis program includes considerations of generic corrective actions needed for equipment of the same make and model.

Discussion: The cog engineer is responsible for reviewing follow-up actions for impact to other similar equipment or same type equipment. Any additional action or rework required is identified by the cog engineer.

Additional follow-up of root-cause efforts enhancing future analysis is performed in accordance with existing WHC site procedures.

Improvement: Existing site procedures and policies are adequate to meet the intent of the DOE Order. Due to the specialization and quantity of equipment types within WSCF, a formalized program for follow up action need not be developed. Cog engineer follow-up is adequate to meet the intent of the DOE Order. Periodic assessment is made to determine if further enhancement to this policy is required. No improvement is required at this time. 


\subsection{Modification Work}

Facility modification work, including temporary modifications, is accomplished under the same basic administrative controls as those applied to facility maintenance activities so there is no increases in risk to facility equipment, environment, or personnel because of the modifications work.

\subsubsection{Maintenance Program Interface with Modifications}

Objective: $\quad$ Modifications are performed in accordance with requirements and limitations of applicable procedures, codes, standards, and specifications.

Discussion: $\quad$ Modifications work performed by WSCF maintenance is in conformance with the requirements of WHC-CM-6-1, WHC-CM-1-8, and applicable maintenance procedures.

Improvement: Existing site procedures and policies are adequate to meet the intent of the DOE Order. Periodic assessment of the program is performed for compliance to the DOE Order. No improvement is identified or required at this time.

\subsubsection{Temporary Repairs or Temporary Modifications}

Objective: $\quad$ Temporary repairs or modifications are reviewed in accordance with the facility modification program prior to implementation. Temporary repairs or modifications are tracked after completion for consideration of permanent corrective action.

Discussion: Temporary repairs and temporary modifications are controlled per the procedural requirements of WHC-CM-6-1 and tracked by the JCS to completion.

Improvement: Existing site procedures and policies are adequate to meet the intent of the DOE Order. Periodic assessment of the program is performed for compliance to the DOE Order. No improvement is identified or required at this time. 


\subsection{Additional Maintenance Management Requirements}

A program is in place to prevent equipment and building damage due to cold weather at any nuclear facility that may be at risk.

\subsubsection{Seasonal Facility Preservation Requirements}

Objective: Cold weather protection program in place to ensure continued safe facility operations is defined and implemented using approved procedures. Program includes criteria for preparation (and suspension), periodic surveillances, and program effectiveness evaluations. Lessons learned are evaluated and appropriate program changes made to prevent recurrence.

Discussion: Seasonal freeze protection at WSCF is performed in accordance with a specific freeze protection plan for the facility. A winterization and a summerization program exist for WSCF. Design changes to accommodate these programs may be required.

Improvement: WSCF performs continuing assessments for immediate seasonal preservation requirements. A program for extreme weather conditions is developed specifically to meet the protection requirements of WSCF. 


\subsection{DEVIATIONS REQUESTED WITH SUPPORTING RATIONALE}

No deviations from the policy requirements identified by DOE Order 4330.4B (DOE 1994) are requested at this time. 


\subsection{IMPLEMENTATION SCHEDULE}

The following is the schedule of activities that are to be accomplished before re-assessment of WSCF maintenance is performed at the specified two (2) year interval after startup. The activities identified are based upon assessment at the time of the writing of this document. Any changes to this schedule may be made as further activity assessment is performed. Scheduled startup is 11-94.

\begin{tabular}{|c|c|c|c|c|c|c|c|}
\hline & \multirow{2}{*}{ ArTIVIT? } & \multicolumn{2}{|c|}{95} & \multicolumn{2}{|c|}{96.} & \multicolumn{2}{|l|}{97 . } \\
\hline & & 17.2 & 3.4. & $1 \%$ & $3 \div 4$ & $1 / 42.6$ & 14. \\
\hline 4.2 .2 & $\begin{array}{l}\text { Maintenance Strategy } \\
\text { - Deyelop a program for long range } \\
\text { maintenance goals } \\
\text { - Develop schedule to support long range } \\
\text { plans }\end{array}$ & & & & $\mathbf{X}$ & & \\
\hline 4.2 .4 & $\begin{array}{l}\text { Goals and Objectives } \\
\text { Update goals }\end{array}$ & & & $\mathrm{X}$ & & & \\
\hline 4.3.1 & $\begin{array}{l}\text { Responsibilities } \\
\text { Review training requirements for WSCF } \\
\text { maintenaance personnel to ensure program is } \\
\text { adequate }\end{array}$ & & & & $\mathbf{X}$ & & \\
\hline 4.3 .2 & $\begin{array}{l}\text { Maintenance Training Program } \\
\text { Review training records to ensure } \\
\text { maintenance personnel have been trained on } \\
\text { specialized equipment. }\end{array}$ & & & & & & \\
\hline 4.3.3 & $\begin{array}{l}\text { Training Schedules and Support } \\
\text { Schedule additional training for maintenance } \\
\text { personnel if required }\end{array}$ & & & & & & \\
\hline 4.3 .4 & $\begin{array}{l}\text { On-The-Job Training } \\
\text { Review equipment requiring OJT }\end{array}$ & & & & $\mathbf{X}$ & & \\
\hline 4.3 .7 & $\begin{array}{l}\text { Training Program Approval, Effectiveness, } \\
\text { and Feedback } \\
\text { Manager WSCF Maintenance reviews } \\
\text { trainnig program for improvement. } \\
\text { Approves program. }\end{array}$ & & & & $\mathbf{X}$ & & \\
\hline 4.4 .1 & $\begin{array}{l}\text { Facilities, shop and satellite areas } \\
\text { Address larger shop area to support } \\
\text { maintenance equipment. }\end{array}$ & & & $\mathbf{X}$ & & & \\
\hline 4.15 .2 & $\begin{array}{l}\text { Performance Indicators, Goals and } \\
\text { Objectives Results. } \\
\text { Identify and formalize goals and objectives, } \\
\text { track goals. }\end{array}$ & & & $\mathbf{X}$ & & & \\
\hline 4.19 .1 & $\begin{array}{l}\text { Seasonal Facility Preservation Requirements } \\
\text { Reassess the program for extreme weather } \\
\text { conditions }\end{array}$ & & $\mathrm{X}$ & & & & \\
\hline
\end{tabular}




\subsection{BIBLIOGRAPHY}

DOE, 1994, Maintenance Management Program, DOE Order 4330.4B, U.S. Department of Energy, Washington, D.C.

DOE, 1991b, Quality Assurance, DOE Order 5700.6C, U.S. Department of Energy, Washington, D.C.

DOE, 1991a, Accreditation of performance-Based Training for Category A Reactor and Nuclear Facilities, U.S. Department of Energy, Washington, D.C.

DOE, 1993, DOE-RL Hanford Site Hoisting and Rigging Manual, DOE-RL-92-36, U.S. Department of Energy, Richland, Wa. 


\section{DISTRIBUTION}

Number of Copies

ONSITE

8

U.S. Department of Energy

Ricland Operations Office

G. A. Gossell

R3-82

T. M. Stram

S7-55

J. M. Hennig (3)

S7-55

Public Reading Room

A1-65

Westinghouse Hanford Company

President's Office

B3-01

M. L. Bell

T6-16

S. L. Brey

T6-12

J. L. Deichman

H4-19

R. R. Grabbe

S3-28

R. R. Harloff

S6-76

J. L. Heinemann

T6-16

E. J. Kosiancic

T6-16

S. L. Layton

H4-19

W. D. Leggett

T6-07

R. P. Marshall

T6-14

W. A. Mooney

T6-29

B. K. Olson

S3-28

D. J. Swaim

B3-51

R. E. Traister

B3-63

D. W. Wilson

S3-30

R. J. Witkowski

S3-30

J. L. Zwicker

T6-14

Central Files

L8-04

Document Clearance Administration

R1-08

Document Processing and Distribution (2)

L8-15

Information Release Administration

A3-36

OSTI (2)

L8-07 